\title{
Optogenetic Control of Spine-Head JNK Reveals a Role in Dendritic Spine Regression
}

\author{
Patrik Hollos, ${ }^{1}$ Jismi M. John, ${ }^{1}$ ĐJukka V. Lehtonen, ${ }^{2}$ and Eleanor T. Coffey ${ }^{1}$ \\ https://doi.org/10.1523/ENEURO.0303-19.2019 \\ ${ }^{1}$ Turku Bioscience, University of Turku and Åbo Akademi University, Turku Fl-20500, Finland and ${ }^{2}$ Biochemistry, \\ Faculty of Science and Engineering, Åbo Akademi University, Åbo FI-20500, Finland
}

\begin{abstract}
In this study, we use an optogenetic inhibitor of c-Jun $\mathrm{NH}_{2}$-terminal kinase (JNK) in dendritic spine subcompartments of rat hippocampal neurons. We show that JNK inhibition exerts rapid (within seconds) reorganization of actin in the spine-head. Using real-time Förster resonance energy transfer (FRET) to measure JNK activity, we find that either excitotoxic insult (NMDA) or endocrine stress (corticosterone), activate spine-head JNK causing internalization of AMPARs and spine retraction. Both events are prevented upon optogenetic inhibition of JNK, and rescued by JNK inhibition even $2 \mathrm{~h}$ after insult. Moreover, we identify that the fast-acting anti-depressant ketamine reduces JNK activity in hippocampal neurons suggesting that JNK inhibition may be a downstream mediator of its anti-depressant effect. In conclusion, we show that JNK activation plays a role in triggering spine elimination by NMDA or corticosterone stress, whereas inhibition of JNK facilitates regrowth of spines even in the continued presence of glucocorticoid. This identifies that JNK acts locally in the spine-head to promote AMPAR internalization and spine shrinkage following stress, and reveals a protective function for JNK inhibition in preventing spine regression.
\end{abstract}

Key words: elimination; hippocampal neurons; kinase; optogenetics; spine; stress

\section{Significance Statement}

Identifying mechanisms that underlie dendritic spine elimination is important if we are to understand maladaptive changes that contribute to psychiatric disease. Compartment-specific, fast-acting tools can expedite this endeavor. Here we use a light-activated inhibitor of c-Jun $\mathrm{NH}_{2}$-terminal kinase (JNK) to control kinase activity specifically in dendritic spines. Light-activation of the JNK inhibitor reduces AMPA receptor removal and spine regression in response to corticosterone and NMDA stress. Furthermore, we find that the anti-depressant drug ketamine lowers JNK activity in hippocampal neurons and prevents spine regression, though direct JNK inhibition is more effective. This study identifies a role for JNK in spine regression and may be relevant for endocrine control of synaptic strength and for conditions where chronic glucocorticoid stress leads to spine elimination.

\section{Introduction}

Dendritic spines account for $>90 \%$ of glutamatergic synapses in the brain and are essential sites for processing electrochemical input (Nimchinsky et al., 2002). New spine growth and synapse formation occur throughout life and stabilization of synapses correlates with memory for-

Received July 30, 2019; accepted December 19, 2019; First published January $14,2020$.

The authors declare no competing financial interests. mation and consolidation (Matsuzaki et al., 2001 ; Noguchi et al., 2011; Attardo et al., 2015; Berry and Nedivi, 2017). Turnover of spines also effects learning and memory performance and transient spines permit Hebbian-like plasticity (Holtmaat and Caroni, 2016). On the other hand, excessive spine elimination is a hallmark of schizophrenia 
and major depressive disorder (Musazzi et al., 2011; Duman and Duman, 2015; Varidaki et al., 2016; Wohleb et al., 2018), and postmortem studies report that there are spine deficits in prefrontal cortex and hippocampus of these individuals (Michelsen et al., 2007; Duman, 2009; Hajszan et al., 2009; Duman et al., 2012; Duman and Aghajanian, 2012; Radley et al., 2013). In addition to this, classical anti-depressant drugs such as fluoxetine and desipramine have been shown to reverse spine loss (Hajszan et al., 2009; Chen et al., 2010; Rubio et al., 2013; McAvoy et al., 2015), suggesting that spine loss may contribute to the underlying pathology. Even the fastacting anti-depressant ketamine has been shown to prevent net spine loss in a rodent chronic stress model, leading to recovery of dysfunctional circuit activity (ModaSava et al., 2019; Treccani et al., 2019). Thus, spine regression while a fundamental feature of normal synaptic plasticity, is also associated with psychiatric disorders. Molecular drivers of spine shrinkage are largely unknown. c-Jun $\mathrm{NH}_{2}$-terminal kinases (JNKs) exert pleiotropic functions during development of the nervous system, regulating cell death and proliferation as well as migration and dendrite arborization (Weston and Davis, 2007; Westerlund et al., 2011; Björkblom et al., 2012; Coffey, 2014; Komulainen et al., 2014). However, JNKs are first and foremost recognized as stress-activated protein kinases that are strongly activated by a variety of cellular stresses including cytokines and glucocorticoids (Qi et al., 2005; Kyriakis and Avruch, 2012), and stress-activated JNK is associated with synaptic deficits in mouse models of Alzheimer's disease (Sclip et al., 2014). Moreover, activation of JNK2 and JNK3 in hippocampus was shown to be necessary for stress-induced learning deficit in mice (Sherrin et al., 2010). It has also been shown that interleukin, $\beta$-amyloid and restraint-stress-induced activation of JNK impairs hippocampal LTP (Curran et al., 2003; Costello and Herron, 2004; Sherrin et al., 2011). Evidence from animal studies and human genetics studies suggest that dysregulation of the JNK pathway may be linked to psychiatric disorders (Winchester et al., 2012; Kunde et al., 2013; McGuire et al., 2017; Mohammad et al., 2018; Kowalchuk et al., 2019; Openshaw et al., 2019). For example, inhibition or genetic deletion of Jnk1 reduces anxiety and depressive-like behaviors in mice (Mohammad et al., 2018), and MAP2K7 heterozygote mice display brain imaging endophenotypes and behaviors related to schizophrenia (Openshaw et al., 2020). Although JNK has been shown to regulate synaptic plasticity in learning and

This work was supported by the Academy of Finland Grants 135090 and 310583 EU FP7 ITN 608346 rBIRTH (to E.T.C.) and by the Molecular Biology Graduate School at Åbo Akademi University (P.H.).

Acknowledgements: We thank the Cell Imaging Core at Turku Bioscience for providing technical support and Biocenter Finland for infrastructure support.

Correspondence should be addressed to Eleanor T. Coffey at eleanor.coffey@bioscience.fi.

https://doi.org/10.1523/ENEURO.0303-19.2019

Copyright (C) 2020 Hollos et al.

This is an open-access article distributed under the terms of the Creative Commons Attribution 4.0 International license, which permits unrestricted use, distribution and reproduction in any medium provided that the original work is properly attributed. the JNK pathway is genetically associated with disorders of synaptic function; mechanistic study of JNK function in dendritic spines has been limited due to lack of tools that allow spatiotemporal control of the kinase solely in the spine-head.

Here, we exploit an optogenetic inhibitor of JNK to control kinase activity in spines. This reveals that stress activated JNK triggers AMPA receptor internalization and rapid spine retraction following activation by NMDA or corticosterone. The antidepressant drug ketamine, suppresses activation of JNK and helps prevent spine loss; however, direct JNK inhibition elicits a faster and more potent block of receptor internalization and spine retraction and reduces spine elimination even when administered $2 \mathrm{~h}$ after glucocorticoid stress. These results indicate that JNK drives dendritic spine regression in response to stress.

\section{Materials and Methods}

\section{Plasmid construction}

Rat $\beta$-actin was obtained by PCR and was ligated to the EcoRI site of the pVenus vector followed by exchanging the Venus tag for mCherry using Nhel/BsRGl sites. NESC-Jun(1-146) was prepared by PCR-based methods from pcDNA3-mJIP1a (Flag-JBD; gift from Martin Dickens, Leicester) and cloned into eGFP-C1 (Clontech). Subsequently, GFP was replaced for mCherry using Nhel/BsrGl sites to yield mCherry-NES-C-Jun(1-146). The photoactivatable pLuc-LOV2WTJ $\alpha$ WT-JBD (LOV2-JBD), the litstate mutant pLuc-LOV2WTJ $\alpha$ IE-JBD and the dark-state mutant pLuc-LOV2C450AJ $\alpha$ WT-JBD, were prepared by ligating JNK interacting protein-1 (JIP1 144-154) "RPKRPTTLNLF" downstream of LOV2 to generate a specific inhibitor of JNK, as previously described (MeleroFernandez de Mera et al., 2017). LOV2 was generated by gene synthesis from Avena sativa LOV2 with codon optimization. GFP-LOV2WTJ $\alpha$ WT (LOV2-JBD) was prepared by PCR insertion of wild-type LOV2 into the pEGFP-C1 vector with overhanging Sall/Sacll sites. To generate a red-shifted Förster resonance energy transfer (FRET) sensor that would not overlap with the LOV2 absorption peak, the JNKAR1EV probe (provided by Michiyuki Matsuda, Kyoto University) was modified by inserting mRuby2 and Clover tags (gifts from Michael Lin, Addgene plasmids \#40260 and \#40259, respectively), in place of ECFP and YPET using EcoRI/Xhol and Notl/Sall sites, respectively. pCl-SEP GluR2 (SEP-GluR2) was a gift from Robert Malinow (Addgene plasmid \# 24001) and eYFP-C1 was from Clontech.

\section{Structure prediction}

To generate an estimated view of possible 3D conformations of the LOV2-JBD tools in dark-state and lit-state, we used MODELLER (Sali and Blundell, 1993). This software uses known Protein Data Bank-derived structures as templates for prediction of least constrained conformations and is reported to generate chemically correct models (Wallner and Elofsson, 2005). PDB ID 2VOU and 2V1A cryo-trapped wild-type and dark-state structures of LOV2 (Halavaty and Moffat, 2007) were used as templates to 
predict the dark-state after alignment with our dark-state mutant. PDB ID 2VOW and 2V1B were used as templates for the lit-state mutant (Heo et al., 2004). Energy minimization used Yet another Scientific Artificial Reality Application (YASARA v16; Krieger et al., 2009). C $\alpha$ atoms were aligned with templates to obtain root mean squared deviation (RMSD) values for the models. The top hit energy minimized model from MODELLER v9.11 was used.

\section{Immunocytochemistry and wide field imaging}

Phosphorylated c-Jun ( $\mathrm{p}-\mathrm{Jun})$ was detected using (1: 200) anti-phospho-c-Jun Ser 63 II (\#9261) from Cell Signaling Technology, which has been shown to be specific (Brecht et al., 2005) and detected with anti-rabbit Alexa Fluor 488, 568, or 405 (1:500) as indicated, from Invitrogen Corporation. Hoechst-33342 and Mowiol mounting media were from Invitrogen. For immunostaining, neurons grown on $13 \mathrm{~mm}$ coverslips were washed once with 1-ml ice-cold PBS and fixed using 4\% PFA for 30 min. After 3 $\times 1 \mathrm{ml}$ washes with PBS, cells were permeabilized using $1 \%$ Triton $X-100$ in PBS for 3 min and washed again $(3 \times$ $1 \mathrm{ml}$ ) with PBS. Non-specific binding was blocked using $10 \%$ fetal bovine serum for $1 \mathrm{~h}$. Primary and secondary antibodies were added consecutively, each for 1-h incubations. Coverslips were mounted in 8- $\mu$ l Mowiol containing DABCO anti-fade and analyzed using a Zeiss LSM780 with appropriate laser illumination. Imaging of $\mathrm{p}-\mathrm{c}-$ Jun and mCherry-NES-Jun was conducted with a Leica DMRE upright microscope and $40 \times$ air objective. Identical acquisition parameters were used for all cells so that the images were quantitatively comparable. Line intensities $(15 \mu \mathrm{m})$ were measured from the dendritic shaft using ImageJ (NIH). Cytoplasmic JNK activity was calculated from non-saturated line intensity ratios: [intensity $\mathrm{p}$-Jun]/ [intensity mCherry-NES-Jun]. Ratiometric images were generated using the Ratio Plus plugin for ImageJ.

\section{Hippocampal neuron isolation and maintenance}

Newborn Sprague Dawley rats of either sex were decapitated and the hippocampus rapidly removed into dissection media [ $1 \mathrm{M} \mathrm{Na}_{2} \mathrm{SO}_{4}, 0.5 \mathrm{M} \mathrm{K}_{2} \mathrm{SO}_{4}, 1 \mathrm{M} \mathrm{MgCl}_{2}, 100$ $\mathrm{mM} \mathrm{CaCl}_{2}, 1 \mathrm{M} \mathrm{HEPES}$ (pH 7.4), $2.5 \mathrm{M}$ glucose, and $0.5 \%$ phenol red]. Meninges were removed and tissue pieces collected into dissection media containing 10\% KyMg, followed by washing. Tissues were incubated with 10 $\mathrm{U} / \mathrm{ml}$ papain (Worthington, 3119) for $15 \mathrm{~min}$ at $37^{\circ} \mathrm{C}$, repeated two times. Papain was inactivated by incubation with $10 \mathrm{mg} / \mathrm{ml}$ trypsin inhibitor (Sigma, T9128) for $2 \times 5$ $\min$ at $37^{\circ} \mathrm{C}$. Tissue was then dissociated by trituration to yield a homogenous solution of cells. Cultures were maintained in Neurobasal-A (Thermo Fisher Scientific), supplemented with $2 \mathrm{mM}$ glutamine, $50 \mathrm{U} / \mathrm{ml}$ penicillin, $50 \mu \mathrm{M}$ streptomycin, and B27 Neuronal supplement (Gibco, Thermo Fisher Scientific). Cells were transfected with a DNA mix comprising $30 \%$ of transgene vector and $70 \%$ of pCMV vector lacking transgene, to give a total of $0.5 \mu \mathrm{g}$ DNA per 24-well plate well, using 7-10 d in vitro (DIV) cells using Lipofectamine 2000 (Thermo Fisher) following the manufacturer's instructions. Experiments were conducted in hippocampal pyramidal cells at 16-18 DIV.

\section{Photoactivation of LOV2 variants}

Cells for live cell imaging were plated on glass bottom dishes (Greiner Bio-One $\mathrm{GmbH}$ ) or in black walled glass bottom dishes (PELCO), when light sensitive constructs were used. Cells transfected with photosensitive constructs were protected from ambient light in a foil-covered dark box for 5 min before imaging. Handling was performed in a darkened room where the computer monitor was set on minimum light level for set-up and switched off during experiments. In experiments where photoactivation was used and subsequently monitored, we used a Zeiss LSM-780 or Zeiss LSM-880 with Airyscan microscope, as indicated. This was equipped with an incubator chamber: $37^{\circ} \mathrm{C}, 5 \% \mathrm{CO}_{2}$, and $10 \times$ objective was used with a 458-nm argon laser, scan speed of $1.68 \mu \mathrm{s} /$ pixel in "live scan" mode for $30 \mathrm{~s}$, followed by immediate fixation with 4\% PFA; 3\% laser power (0.4-mW irradiance) was used for LOV2 illumination, unless otherwise indicated. Regions of interest (ROIs) in dendritic spines were illuminated with the 458-nm laser for $1 \mathrm{~s}$ with $1.68 \mu \mathrm{s} /$ pixel dwell speed using $63 \times 1.2 \mathrm{~W}$ objective. For Figure $1 F$, where field illumination was used, hippocampal neurons in a 24-well plate were illuminated by placing $40 \mathrm{~cm}$ below a fluorescent lamp (Phillips, PL-2 11W/865/2P ICT/25) for $30 \mathrm{~s}$ followed by immediate fixation of cells with $4 \%$ PFA.

\section{FRET imaging and analysis}

FRET analysis was performed using the Zeiss FRET module. Control (acceptor or donor alone) and FRET images were acquired by using the Lambda stack scan mode on the Zeiss-LSM 780 to achieve appropriate spectral separation. For mRuby2-JNKAR1EV-Clover FRET imaging, the donor (Clover) was excited using $0.4 \mathrm{~mW}$ of a $488 \mathrm{~nm}$ laser and a $63 \times$ objective. mRuby2 was excited using $0.24 \mathrm{~mW}$ of a $543 \mathrm{~nm}$ laser. LOV2 was excited using $0.4 \mathrm{~mW}$ of a $458 \mathrm{~nm}$ laser. To calculate FRET efficiency, several ROls were drawn on dendrites, and Youvan's method was used to calculate the FRET response as follows: $F c=\left(\right.$ fret $\left._{g v}-b g_{\text {fret }}\right)-c f_{d o n} *\left(d o n_{g v}-b g_{d o n}\right)-$ $c f_{a c c} *\left(a c c_{g v}-b g_{a c c}\right)$, where: $F c=$ FRET concentration, $g v=$ gray value intensity, $b g=$ background intensity, don $=$ donor image, acc $=$ acceptor image, $c f=$ correction factor. To compare FRET efficiency between different cellular compartments, normalized FRET (N-FRET) values were calculated as following N-FRET: Ff - ([don $\left.{ }_{\text {corr }}\right]$ $\left[a_{c c} c_{c o r l}\right) / V[(G(F d)(F a)]$, where $F f$ the FRET image in FRET channel, don $n_{\text {corr }}=$ donor image with donor excitation, $a c c_{c o r r}=$ acceptor image with acceptor excitation, $F d=$ emission cross talk of the donor in the FRET channel, $\mathrm{Fa}=$ emission cross talk of the acceptor in the FRET channel, $G=$ donor emission factor in the donor channel due to FRET, relative to the acceptor emission due to FRET in the FRET channel.

\section{Measurement of actin dynamics in dendritic spines}

Hippocampal neurons expressing mCherry-actin (or GFP-actin as indicated) together with LOV2 variants (as indicated), were imaged using a Zeiss-LSM 780 (or LSM880 in Airyscan mode where indicated) microscope and a $63 \times$ objective (C-Apochromat, 1.2 numerical aperture) for live cell imaging or with a Zeiss LSM-880 Airyscan micro- 
A

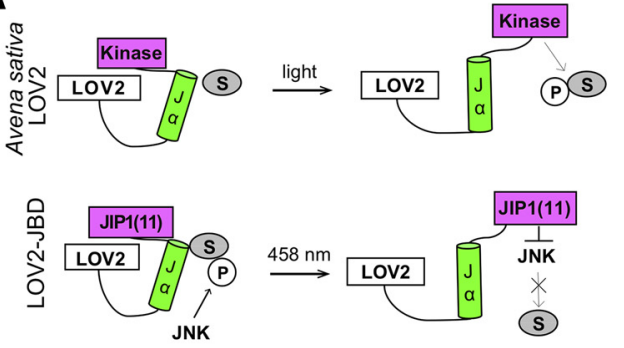

C
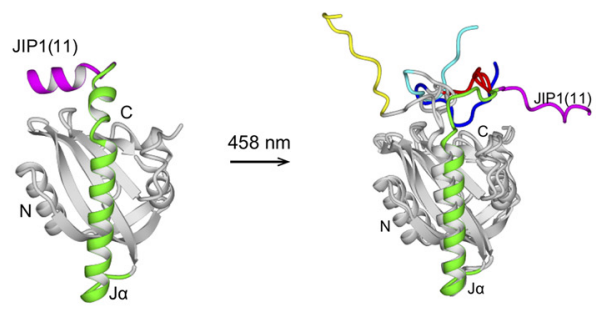

B

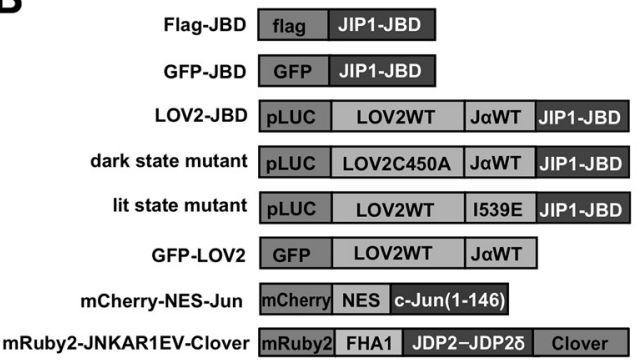

E

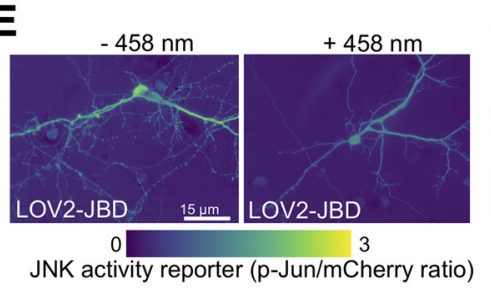

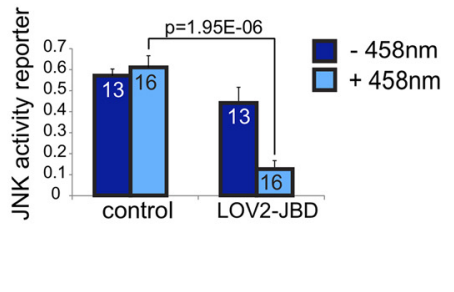

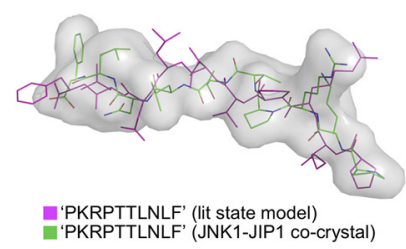

$F$

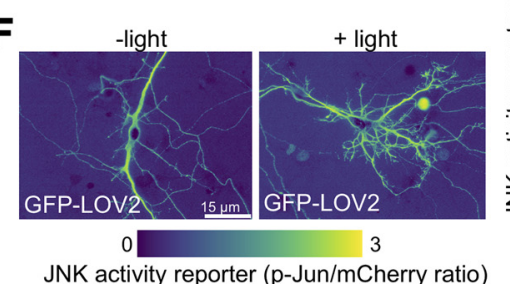

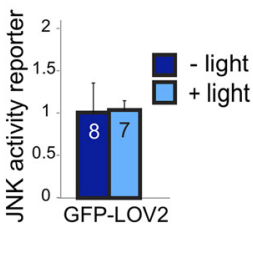

Figure 1. Design and validation of the LOV2-JBD inhibitor. A, Schematic showing activation of LOV2 photo-domain from Avena sativa by light. The proposed mode of action of LOV2-JBD is shown in the lower panel where an 11-mer peptide inhibitor of JNK is released from the constrained conformation on photostimulation, facilitating binding to and inhibition of JNK. $\boldsymbol{B}$, Constructs used in this study. $\boldsymbol{C}$, Superimposed, top five lit-state model predictions for LOV2-JBD. In the top-ranked model, JIP1(11) (magenta) takes on a relaxed conformation projecting away from the core. $\boldsymbol{D}$, JIP1(11) from the lit-state model (magenta) superimposed on the crystal structure of JIP1(11) from the JNK1-JIP1 co-crystal (green). $\boldsymbol{E}$, mCherry-NES-Jun fluorescence provides a surrogate reporter of JNK activity in hippocampal neurons expressing mCherry-NES-Jun (control) or mCherry-NES-Jun with LOV2-JBD. Reporter activity is fluorescence intensity of phosphorylated C-Jun (P-Jun)/mCherry fluorescence intensity. Photostimulation of LOV2-JBD reduces JNK activity in hippocampal neurons; however $(\boldsymbol{F})$ photostimulation of GFP-LOV2 does not. Data on dark-state and lit-state mutants are in Extended Data Figure 1-1. Mean data \pm SEM and Student's $t$ test $p$ values are shown. Cell numbers (from at least two experimental repeats) are indicated on the bars.

scope for live-cell 3D imaging of spines. A 543-nm laser at $3 \%$ power was used to image mCherry-actin, and a $488-\mathrm{nm}$ laser at $6 \%$ power for GFP-actin (Fig. 2 only), in dendritic spines from secondary dendrites, located 20-30 $\mu \mathrm{m}$ from the soma were measured. The stack registration plugin from ImageJ was used to correct $x, y$ drift from time-lapse series and images were then median filtered with 1-pixel radius to enhance the signal-to-noise ratio. Scan speed was $1.68 \mu \mathrm{s} /$ pixel and the time between frames was $6 \mathrm{~s}$. For fast 3D Zeiss LSM-880 Airyscan imaging, scan speed was $\sim 150 \mathrm{~ms}$ for every $0.22 \mu \mathrm{m}$ $z$-slice. Photoactivation of LOV2-constructs was achieved using the 458-nm laser line at 3\% laser power (0.4-mW).

The motility of GFP, mCherry-actin or YFP within spines was quantified using arithmetic difference projection analysis as described by (Fischer et al., 1998; Björkblom et al., 2012). Displacement images were generated between consecutive frames of 6-s interval and the sum of all displacement is projected. These provided a $2 \mathrm{D}$ quantitative view of movement across the time frame where pixel intensity corresponds to actin displacement. Arithmetic projec- tions were inverted for visualization. The "motility index" describes the average intensity in ROls from arithmetic projections. The "motility ratio" was the ratio of motility indices obtained before and after light activation. To view the temporal detail of dynamic changes, RGB temporal color-coded difference projections were generated using frame-by-frame difference stacks. For this we used the ImageJ Hyperstack color-code plugin with customized LUT. A white, or Gaussian mix of colors indicates continuous motility. Each time frame is represented by a unique hue. For these fast motility measurements, LSM-880 Airyscan images were acquired in fast-scan mode, taking a $6 \times 6 \times 4(x y z) \mu \mathrm{m}$ voxel scan approximately every second.

\section{Measurement of synaptic GluR2 receptors and spine-head volume}

To measure surface GluR2 levels at synapses, hippocampal neurons expressing SEP-GluR2 (which undergoes fluorescence quenching on internalization into endocytic vesicles) and mCherry-actin underwent timelapse imaging for 40 min using the Zeiss LSM-880 in 
A

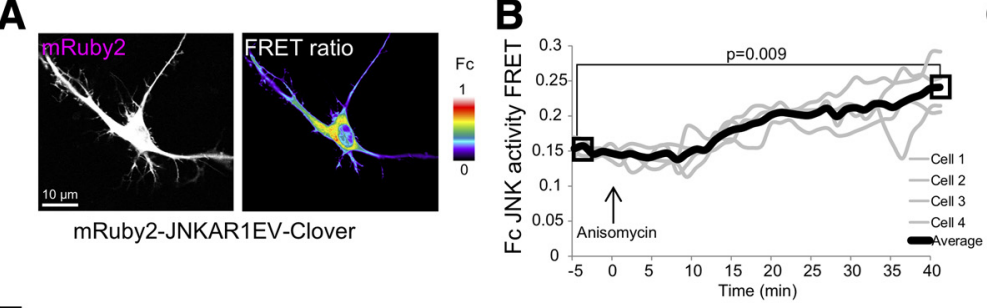

E

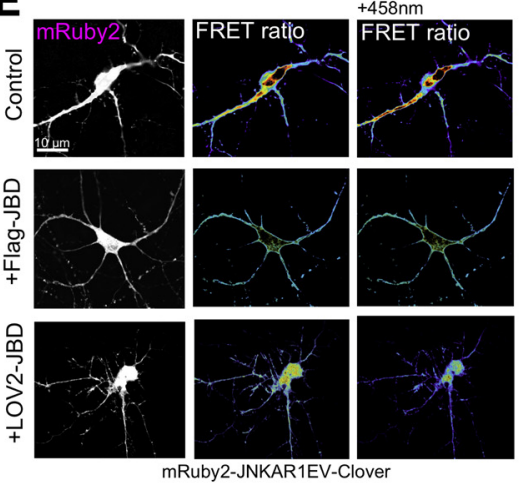

$\mathbf{F}$

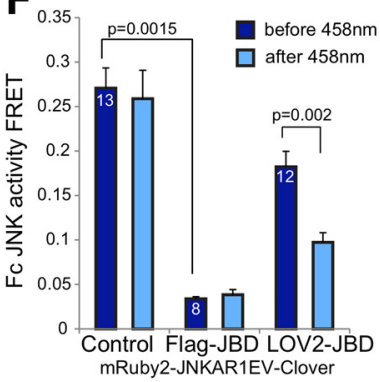

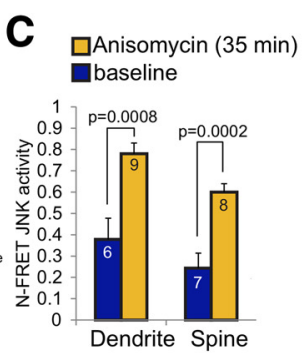

G

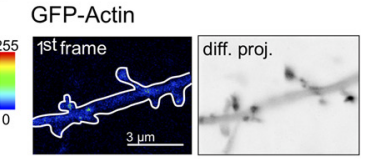

GFP-Actin +

LOV2-JBD "dark state"

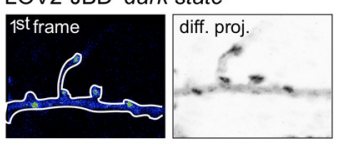

D

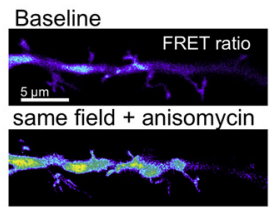

H

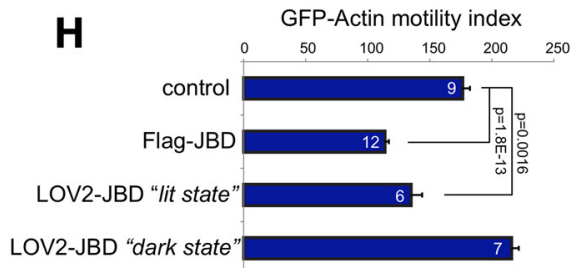

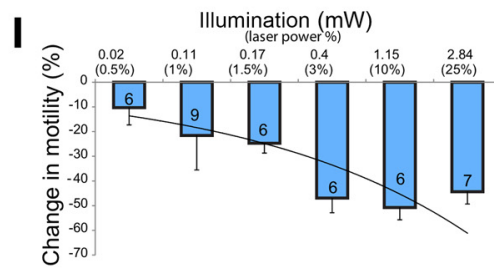

Figure 2. Photoactivation of LOV2-JBD reduces actin dynamics in dendritic spines. $\boldsymbol{A}$, Hippocampal neurons expressing mRuby2JNKAR1EV-Clover FRET reporter provide a real-time readout of JNK activity. The mRuby2 image (left) indicates reporter expression and FRET image (right) indicates JNK activity, which is high in the cytoplasmic compartment. The look up table (LUT) shows FRET ratios $(\mathrm{Fc})$ from 0 to 1. B, mRuby2-JNKAR1EV-Clover FRET reporter activity from hippocampal neuron dendrites increases following JNK activation following anisomycin $(10 \mu \mathrm{M})$ treatment. $\boldsymbol{C}, \mathrm{N}$-FRET shows that JNK is activated in dendrites and spines 40 min following anisomycin $(10 \mu \mathrm{M})$. Mean data \pm SEM are shown; $\mathrm{p}$ values are from Student's t test. Extended Data Figure 2-1 shows mRuby2-JNKAR1EV-Clover FRET has improved dynamic range compared to YPET-JNKAR1EV-CFP. D, Representative image of mRuby2-JNKAR1EV-Clover FRET in dendritic spines. $\boldsymbol{E}$, FRET images from live cell analysis indicate Flag-JBD inhibits JNK, as does LOV2-JBD following photostimulation for $30 \mathrm{~s}$ with $0.4 \mathrm{~mW}$ of $458-\mathrm{nm}$ laser. $\boldsymbol{F}$, Corrected FRET (Fc) from multiple experiments as described in $\boldsymbol{E}$. Measurements were from five regions of interest per cell, from four cells from at least two experimental repeats. Mean data \pm SEM are shown. Adjusted $p$ values are shown from repeated measures one-way ANOVA with Bonferroni correction. Extended Data Figure 2-2 shows independent readout of JNK activity changed due to excitation of the FRET probe with 488-nm laser. G, GFP-actin displacement is shown in arithmetic difference projections (diff. proj.) depicting summed GFP-actin displacements from 11-min imaging. Darker pixels represent higher motility. Scale bar $=3 \mu \mathrm{m}$. $\boldsymbol{H}$, Calculated motility index from several recordings as described in G. Flag-JBD and LOV2-JBD lit-state mutants significantly reduce spine motility. Mean data \pm SEM are shown. Adjusted $p$ values are shown from repeated measures one-way ANOVA with Bonferroni correction $\boldsymbol{I}$, The minimal illumination required to photoactivate LOV2-JBD is shown. Motility changes from neurons expressing mCherry-actin plus LOV2-JBD and exposed to increasing 458-nm illlumination are shown; $0.4 \mathrm{~mW}$ (achieved using 3\% laser power) was the minimum irradiance needed to elicit a maximal response. Motility was calculated from four to six spines per cell and two to three cells per condition from at least two experimental repeats.

Airyscan mode using the $488-\mathrm{nm}$ laser at $0.8 \%(0.19 \mathrm{~mW})$ power so as to minimize inadvertent photoactivation of LOV2. Fluorescence intensity for each fluorescent protein was measured from circular ROls in spines. To determine relative GluR2 surface expression, the ratio of SEP-GluR2 to mCherry-actin or YFP was calculated. To analyze spine head volume, $\mathrm{ROI}$ voxels were drawn encompassing the entire volume occupied by visible mCherry-actin or YFP in the spine head throughout the time lapse as previously (Basu et al., 2018; Hruska et al., 2018), ensuring that the entire 4D footprint was included in the analysis. The $z$-depth was $4 \mu \mathrm{m}$ and $x, y$ dimensions varied according to individual spine size. Spines were imaged in 3D with a $z$-section of $0.2-\mu \mathrm{m}$ scan speed of three frames per second. Relative changes in dendritic spine volume were estimated from maximum intensity projections from these images. To calculate a baseline spine volume, maximum projections from 3 min of image acquisition before treatment were averaged. Subsequent recordings were normalized to this value. For fixed cell analysis, relative changes in dendritic spine volumes and SEP-GluR2 to mCherry-actin ratios were normalized to control condi- 
tions (before treatment). Boundaries of spine heads were drawn from maximum intensity images where the border was defined by change in signal:noise $>10$ compared to mean background.

\section{Hippocampal neuron pharmacological treatments}

Anisomycin (Sigma) was added at $10 \mu \mathrm{M}$ concentration in growth media to hippocampal neurons during live cell imaging after $5 \mathrm{~min}$ of baseline recording. To produce chemical long-term depression (LTD), hippocampal neurons at 16-18 DIV were treated with $20 \mu \mathrm{M}$ NMDA (Tocris Biosciences) for 3 min in Neurobasal-A, after which conditioned growth medium was added back, as previously described (Lee et al., 1998). Corticosterone (100 nM; Sigma-Aldrich Finland Oy) was added to hippocampal neurons following $5 \mathrm{~min}$ of baseline recording or $2 \mathrm{~h}$ before or after ketamine treatment as indicated. Ketamine (10 $\mu \mathrm{M}$; Tocris Biosciences) was added to hippocampal neurons $2 \mathrm{~h}$ before recording. Latrunculin $\mathrm{B}(1 \mu \mathrm{M}$; Sigma-Aldrich Finland Oy) or Phalloidin (500 nm; SigmaAldrich Finland Oy) was added to hippocampal neurons following $5 \mathrm{~min}$ of baseline recording.

\section{Statistical analysis}

Student's two-tailed $t$ tests were used to calculate $p$ values where two groups were compared. Repeated measures one-way ANOVA was used to compare multiple groups and $p$ values were corrected by Bonferroni correction. Error bars represent SEM. In each case, measurements were taken from multiple cells and spines from separate experiments, and statistical analysis is detailed in the corresponding legend.

Animal procedures were performed in accordance with the Turku Central Animal Laboratory regulations and national guidelines.

\section{Results}

We generated an optically controllable inhibitor of JNK to enable localized inhibition of JNK function exclusively in dendritic spines without altering JNK activity in other compartments. To do this, we replaced the kinase domain from $A$. sativa phototropin with an 11-mer peptide inhibitor of JNK (JNK binding domain; JBD), a highly specific peptide inhibitor of JNK which does not inhibit other MAPKs (Bonny et al., 2001; Borsello et al., 2003; Fig. 1A). We hypothesized that in the absence of light, steric hindrance conferred by a constrained $\mathrm{J} \alpha$ helix would prevent JBD from binding and inhibiting JNK, thereby allowing unhindered function of the kinase within the cell. Conversely, on illumination, relaxation of the $\mathrm{J} \alpha$ helix should release this constraint and facilitate kinase inhibition.

\section{An optically controlled JNK inhibitor assumes an inward-pointing, constrained dark-state and outward-pointing extended lit-state conformation}

To validate LOV2-JBD as a light-regulated JNK inhibitor, we used a dark-state mutant of LOV2 encoding a C450A mutation in the photo-sensing domain to impose a constrained conformation (Salomon et al., 2000), and a lit-state mutant with I539E mutation in the $\mathrm{J} \alpha$ helix, that imposes a relaxed conformation (Harper et al., 2004; Fig.
$1 B)$. Using homology modeling, we found that both litstate and dark-state mutant $\mathrm{C} \alpha$ atoms aligned well to the crystallographic reference structure for LOV2 with RMSDs of 0.52 and $0.57 \AA$, respectively (Fig. 1C). Also, the top five $\mathrm{J} \alpha$ helix models retained six $\alpha$-helical turns consistent with crystallographic and NMR A. sativa LOV2 (Halavaty and Moffat, 2007; Peter et al., 2010). However, the tandem-encoded 11-mer JBD switched from an inward pointing $\alpha$-helix in the dark-state mutant to an extended conformation that projected away from LOV2 in the litstate mutant (Fig. 1C). Notably, the relaxed conformation of the lit-state mutant JBD was similar to the structure of JIP1(11) bound to JNK1 (Heo et al., 2004), consistent with this being an inhibitory conformation (Fig. 1D). Alignment of $\mathrm{C} \alpha$ atoms gave an overall RMSD of $1.68 \AA$, indicating close alignment between the structures (Fig. 1C,D). These data predicted that the LOV2-JBD light sensing $\mathrm{J} \alpha$ helix would undergo a conformational change on blue light exposure analogous to that of phototropin-LOV2 (Peter et al., 2010; Fig. 1), leading to a relaxed JBD inhibitor conformation, suitable for trans-inhibition of enzymatic activity (Heo et al., 2004).

\section{Proof of concept that LOV2-JBD inhibits JNK in response to light}

To test experimentally whether LOV2-JBD could be induced by light to inhibit JNK in hippocampal cells, we first measured the phosphorylation of mCherry-NES-Jun as a surrogate reporter of JNK activity in the cytoplasm of transfected cells. Hippocampal neurons displayed elevated phosphorylation of mCherry-NES-Jun, consistent with the high basal activity of JNK in thee cytosol that is characteristic of neurons (Coffey et al., 2000; Coffey, 2014). In cells expressing LOV2-JBD, photoactivation using 458-nm laser substantially reduced JNK activity (Fig. $1 E$ ). Importantly expression of GFP-LOV2 alone did not alter JNK activity (Fig. 1F), indicating that the JBD sequence was required and that LOV2 alone did not affect JNK activity.

\section{JNK is catalytically active in dendritic spines and can be optically controlled}

To visualize real-time JNK activity in neurons, we modified an intramolecular FRET reporter (JNKAR1EV; Komatsu et al., 2011) by substituting mRuby2/Clover for the ECFP/YPET FRET pair to generate a reporter that had increased sensitivity (Extended Data Fig. 2-1B), and minimal spectral overlap with LOV2-JBD. Baseline measurements in hippocampal neurons indicated that JNK activity was elevated not only in dendrites, as previously shown (Björkblom et al., 2005), but also in dendritic spines (Fig. $2 A)$. After treatment with anisomycin, an activator of JNK (Cano et al., 1994), FRET activity increased further in dendrites and spines (Fig. 2B-D), whereas on expression of the Flag-JBD inhibitor, reporter activity decreased by $90 \%$ (Fig. 2E,F). These data indicate that mRuby2JNKAR1EV-Clover provides a sensitive and specific measure of JNK activity in living neurons. We next used mRuby2-JNKAR1EV-Clover to test optogenetic inhibition of JNK. Photostimulation of LOV2-JBD using 458-nm illumination decreased FRET reporter activity by $50 \%$ (Fig. 
$2 E, F)$, whereas in cells expressing FRET reporter alone, 458-nm illumination had no effect (control), indicating that light-induced inhibition of JNK FRET reporter activity required LOV2-JBD. In these experiments, we did observe a moderate inhibition of JNK activity in cells expressing LOV2-JBD merely on 488-nm excitation of mRuby2JNKARIEV-Clover. The extent of inhibition was $30 \%$, as validated also with an independent JNK activity reporter (Extended Data Fig. 2-2).

\section{JNK activity regulates dendritic spine motility}

The effect of JNK on dendritic spine motility was measured using arithmetic difference projection images of GFP-actin generated from a time-series (Fig. 2G). Dendritic spines were highly motile in 16-DIV hippocampal neurons, in cells expressing Flag-JBD, spine-head movement was blocked (Fig. 2G,H). Cells expressing the litstate LOV2-JBD mutant also exhibited reduced motility, whereas neurons expressing the dark-state mutant which fails to inhibit JNK (Extended Data Fig. 1-1A,B), did not show altered dynamics (Fig. 2G,H). We found that a relatively low illumination of $0.4 \mathrm{~mW}$ was sufficient to reduce spine motility (Fig. 2/), and we used this "threshold" setting for photoactivation of LOV2-JBD from here on so as to avoid photo-toxic effects.

\section{JNK acts locally within the spine-head to control spine motility}

We next exploited the spatiotemporal control of optogenetic inhibition to examine JNK regulation of spine motility in more detail by specifically illuminating the inhibitor in the spine-head. In the absence of 458-nm light, there was rapid displacement of mCherry-actin in the head and neck of the spine and prominent re-shaping or morphing (Fig. $3 A$ ). Selective ROI photostimulation of LOV2-JBD solely in the spine-head was sufficient to reduce mCherry-actin motility; however, cells expressing the dark-state LOV2-JBD mutant remained unaltered (Fig. $3 A-C)$. Notably, there was no change in motility observed in the proximal dendrite or in non-illuminated spines (Fig. $3 A-C$ ), indicating that $\mathrm{JNK}$ exerts rapid control of actin movement from within the spine-head (Extended Data Fig. 3-1A).

\section{JNK controls motility of spines with small "head diameter to neck length" ratios}

Mature dendritic spines consist of large, mushroomshaped protrusions; yet both thin and mushroom spines can appear and disappear throughout adulthood and are important for synaptic plasticity (Holtmaat et al., 2008). To define which spine-type is primarily regulated by JNK, we analyzed spines of different size categories. We defined spines according to the average head diameter to neck length ratio assumed by a given spine during the imaging sequence, as previously (Murase et al., 2016). Interestingly, JNK inhibition reduced motility only in spines that had an average head to neck ratio of between 0.2 and 1.5, corresponding to "thin" and "long thin" spines (Fig. 3D). In contrast, photostimulation of LOV2-JBD in mushroom spines (head diameter:neck length ratio $>3$ ), did not alter dynamics, even when laser power was increased to ac- count for larger spine-head volume (Extended Data Fig. $3-1 B$ ). This data indicate that JNK specifically regulates the motility of thin spines.

\section{JNK exerts rapid control over spine motility}

Protein phosphorylation is a highly dynamic process. We therefore measured how quickly a photoactivated JNK inhibitor (LOV2-JBD) could affect actin motility (Fig. $3 E, F)$. In neurons expressing LOV2-JBD, exposure to a 1-s pulse of 458-nm light was sufficient to rapidly inhibit mCherry-actin motility within $6 \mathrm{~s}$ of photostimulation. Motility returned to baseline by $2 \mathrm{~min}$ (Fig. 3E). We used temporal color coding to obtain spatiotemporal information on actin regulation. Time projection images revealed that optogenetic inhibition of JNK halted actin dynamics by $2 \mathrm{~s}$ (blue) in the periphery of the spine and movement did not resume in this region during $90 \mathrm{~s}$ of monitoring (Fig. 3G,H). Interestingly, actin motility decreased in a polarized fashion, starting on one side of the spine-head (blue) and progressing to the opposite side by $5 \mathrm{~s}$ (green), whereas the core domain of actin in the spine center remained motile (white) on JNK inhibition (Fig. 3H; Extended Data Fig. 3-1C-E). These data suggest that JNK controls actin dynamics in the peripheral domain of the spine.

To help understand the contribution of actin dynamics to the spine motility changes measured, we treated neurons with either latrunculin (which binds G-actin and prevents polymerization), or phalloidin (which binds and stabilizes F-actin; Saito, 2009). Latrunculin treatment of neurons reduced spine motility (Fig. $3 /, J$ ) and yielded a characteristic "blue" time projection image suggesting that inhibition of $\mathrm{F}$-actin formation reduced spine dynamics (Fig. 3K). In contrast, phalloidin-treated neurons maintained spine motility (Fig. $3 /, J$ ) and showed a distribution of movements throughout the 90-s monitoring (Fig. 3K). The temporal coding pattern observed with optogenetic inhibition of JNK is similar to that obtained with latrunculin suggesting dissolution of F-actin.

\section{JNK is activated by corticosterone leading to internalization of AMPAR and rapid spine retraction}

We were interested to know whether JNK regulated spine retraction in the context of synaptic pathology because JNK1 was recently reported to control depressive and anxiety-like behaviors in mice (Hollos et al., 2018; Mohammad et al., 2018). We therefore used corticosterone, the principal glucocorticoid stress hormone in mice, which stimulates retraction of dendritic spines in specific brain regions (Liston and Gan, 2011). JNK activity was measured in hippocampal neurons expressing mRuby2JNKAR1EV-Clover as earlier (Fig. 2). Corticosterone (100 $\mathrm{nM}$ ) increased JNK activity within $10 \mathrm{~min}$ in dendritic and spine compartments (Fig. 4A,B).

As AMPA receptor removal from the synapse is an early event during spine shrinkage (Hanley, 2014), we next investigated whether corticosterone would affect this process. GluR2 endocytosis was visualized as previously 
A mCherry-Actin Q 5 \& 3 \& 0s $6 s \quad 12$ s $18 \mathrm{~s} 24 \mathrm{~s} 30 \mathrm{~s} 36 \mathrm{~s} 42 \mathrm{~s} 48 \mathrm{~s} 54 \mathrm{~s} 60 \mathrm{~s} 66 \mathrm{~s}$ mCherry-Actin + LOV2-JBD "dark state" mutant

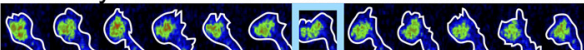
$0 s \quad 6 s \quad 12 s 18 s$ 24s 30s 36s 42s 48s 54s60s 66s mCherry-Actin + GFP-JBD

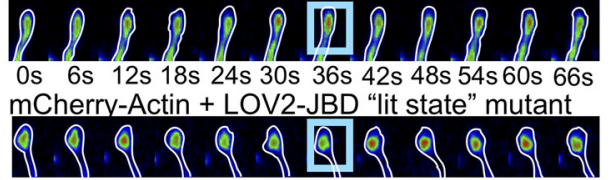

0s $6 s$ 12s 18 s 24 s 30 s $36 s$ 42s 48 s 54 s60s $66 s$ mCherry-Actin + LOV2-JBD

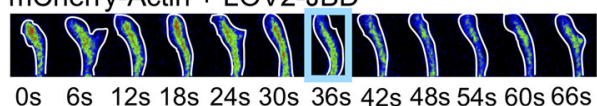

0s $6 s \quad 12 s$ 18s 24 s 30 s $36 s$ 42s 48s 54 s 60 s 66 s

B

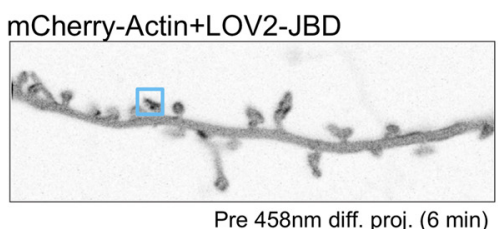

mCherry-Actin+LOV2-JBD

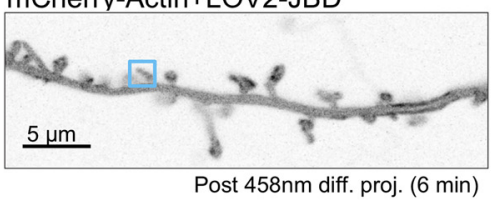

C

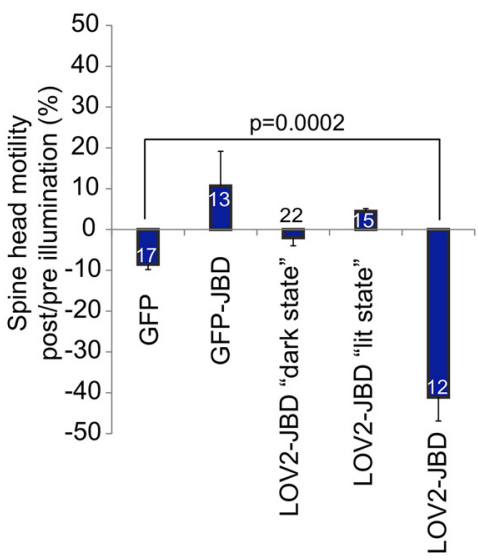

D

Control LOV2-JBD

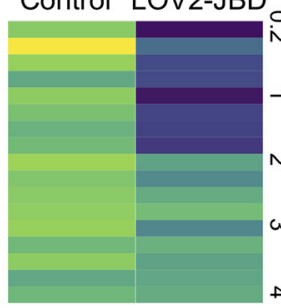

$-60 \%$

Change in motility
E

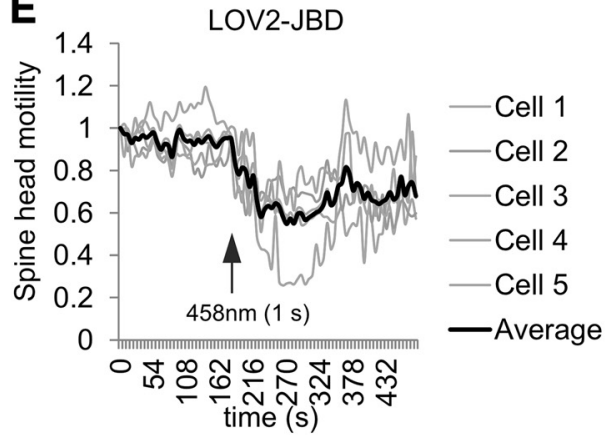

$\mathbf{F}$

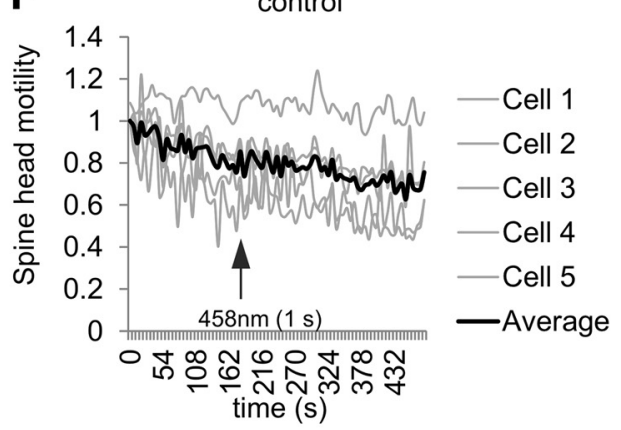

G

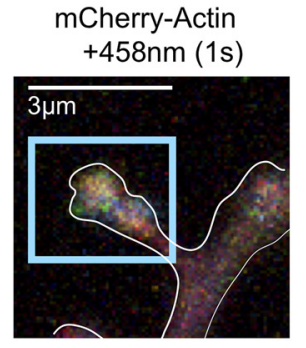

90 s difference projection

I

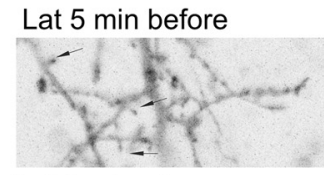

Lat 5 min after

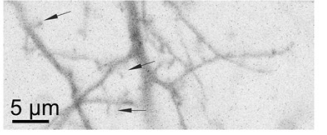

mCherry-Actin+ LOV2-JBD+458nm (1s)

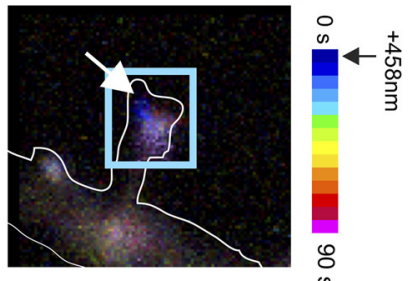

Phall 5 min before

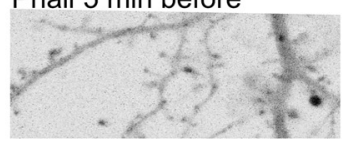

Phall 5 min after

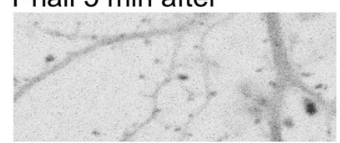

H mCherry-Actin $+458 \mathrm{~nm}(1 \mathrm{~s})$

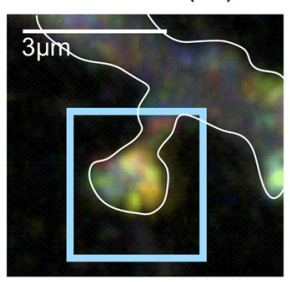

10 s difference projection
LOV2-JBD+458nm (1s)

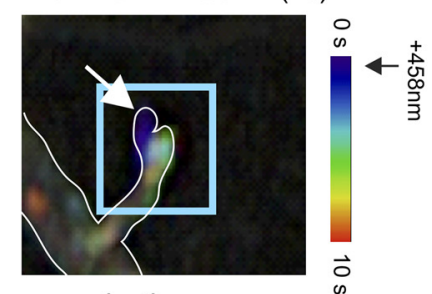

$\mathbf{K}$

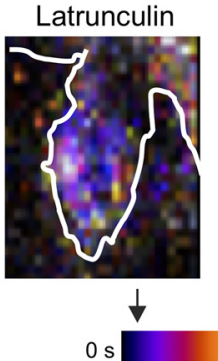

Phalloidin

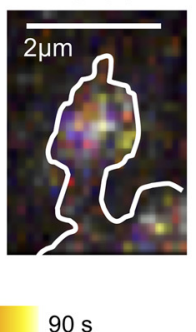

Figure 3. Photoactivation of the LOV2-JBD inhibitor rapidly reduces actin motility in the peripheral domain of the spine. $\boldsymbol{A}$, Time-lapse sequences from 16-d hippocampal neurons expressing mCherry-actin and LOV2-JBD variants. ROls (blue squares) encompassing spine-heads were photostimulated for $1 \mathrm{~s}$ at $36 \mathrm{~s}$ using $0.4 \mathrm{~mW}$ of 458-nm light. Spine-head motility was reduced following light only in cells expressing LOV2-JBD. Additional examples are in Extended Data Figure 3-1A. B, Arithmetic difference projections of mCherry-actin before (pre) and after (post) 458-nm illumination of the spine (blue box). LOV2-JBD immobilized mCherry-actin in photoactivated spines only. Dendritic shaft mCherry-actin was unchanged. C, Quantitative data on mCherry actin motility. Mean data \pm SEM are shown. Spine numbers are indicated on the bars. $\boldsymbol{D}$, mCherry-actin motility changes are plotted according to spine head diameter:neck length ratio. Data from spines with head diameter:neck length ratios corresponding to "mushroom" spines is in 
continued

Extended Data Figure 3-1B. E, Time-lapse of spine-head mCherry-actin motility shows LOV2-JBD immobilizes actin motility within $6 \mathrm{~s}$ of photoactivation. $\boldsymbol{F}$, Light alone does not alter actin dynamics. For E-F, more than or equal to four spines were measured per cell. G, Color-coded time projections provide spatial information on mCherry-actin motility over $90-s$ recording. Photoactivation is at $0 \mathrm{~s}$. Images are acquired at 6-s intervals and coded with a unique hue (LUT). Mixed color (white-ish) indicates continued motility over time. Blue indicates no further movement after that time point. LOV2-JBD-expressing neurons display reduced motility following light. $\boldsymbol{H}$, Higher resolution maximum projections of temporally color-coded dendritic spines are shown from 10-s time lapses acquired at 1-s intervals. These show mCherry-actin is immobilized in the spine periphery. Additional examples with actin footprints and movies generated from the time lapses are in Extended Data Figure 3-1C-E. I, The effect of latrunculin and phalloidin on dendritic spine motility were tested. Arithmetic projection images before and after 458-nm light indicate effect on actin dynamics. $J$, Quantitative data from $\boldsymbol{I}$ indicate that latrunculin reduces actin motility. Measurements are from $\geq 10$ cells and multiple spines from separate experiments. Mean data \pm SEM are shown. $\boldsymbol{K}$, Temporal color coding of spines from neurons treated with latrunculin or phalloidin are shown.
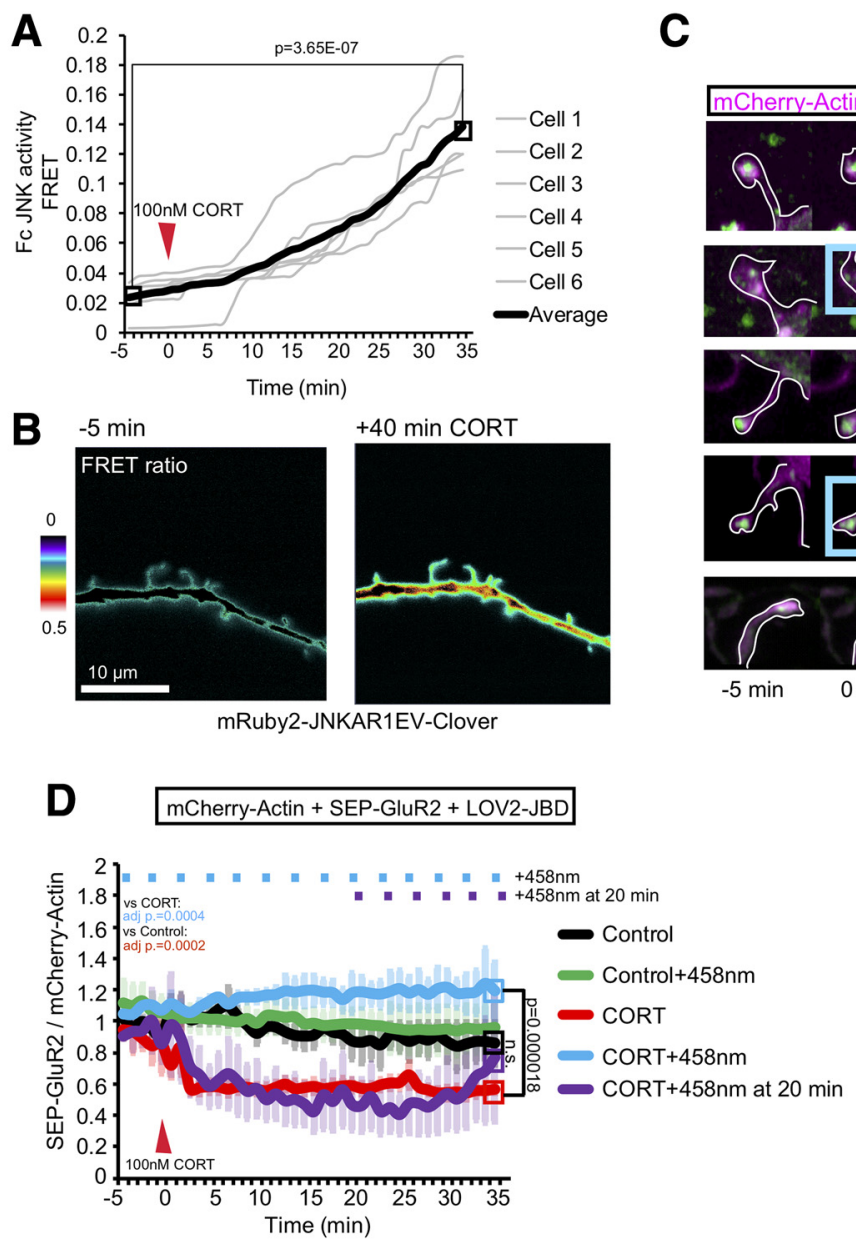

C
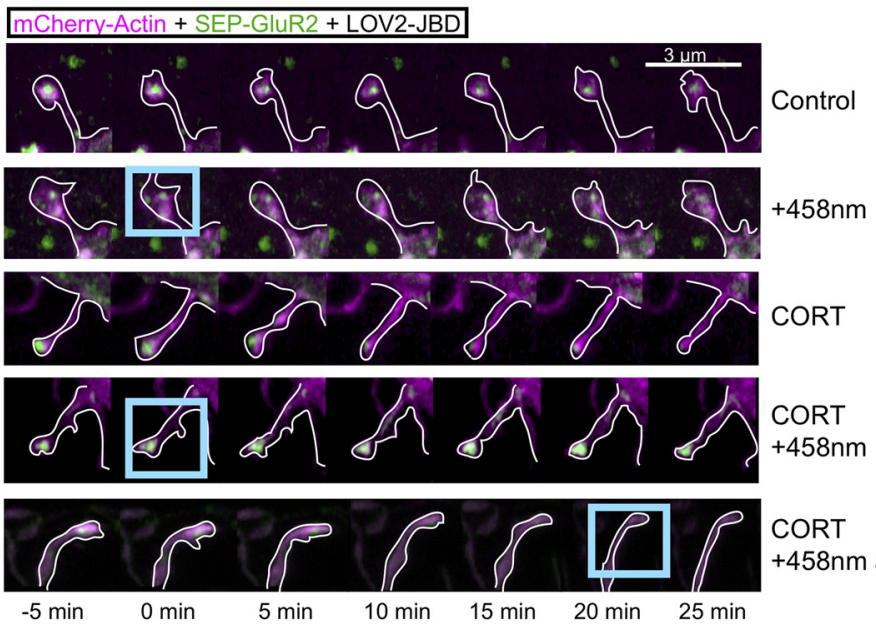

CORT

$+458 \mathrm{~nm}$ at $20 \mathrm{~min}$
E mCherry-Actin + SEP-GluR2 + LOV2-JBD

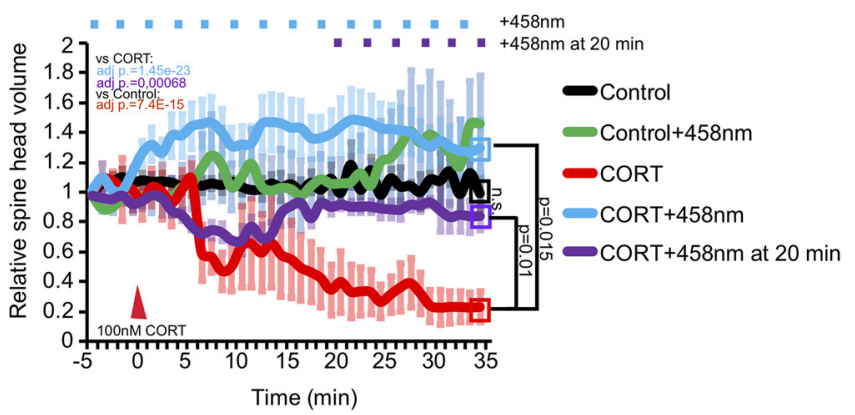

Figure 4. Corticosterone activates JNK and induces SEP-GluR2 removal and spine regression. A, Time-lapse recording of JNK activity in dendritic spines after corticosterone (CORT) application. Normalized Fc FRET is from six cells and more than or equal to four spines per cell. $\boldsymbol{B}$, Representative FRET ratio images from mRuby2-JNKAR1EV-Clover expressing cells. $\boldsymbol{C}$, Representative images of time-lapse sequences $(\boldsymbol{D}, \boldsymbol{E})$ from 16-d hippocampal neurons expressing mCherry-actin (magenta), SEP-GluR2 (green), and LOV2-JBD. Cells were treated with CORT (100 nM) at $0 \mathrm{~min}$, and LOV2-JBD was photoactivated using 458-nm 1-s light pulses (using $3 \%$ laser power, LSM-880 Airyscan) applied to ROI (blue boxes) at 3-min intervals where indicated (+458 $\mathrm{nm})$, or in lower panels, after a 20 min delay. SEP-GluR2 was imaged using the $488-n m$ laser ( $0.8 \%$ laser power with LSM-880 Airyscan), to minimize crossactivation of LOV2-JBD. $\boldsymbol{D}$, Quantitative data on cell surface SEP-GluR2 fluorescence is from eight experiments as depicted in $\boldsymbol{C}$. $\boldsymbol{E}$, Estimated spine-head volume is normalized to baseline volume, averaged over 3 min before treatment. Extended Data Figure 4-1 shows experiments repeated as in $\boldsymbol{C}-\boldsymbol{E}$ with CORT treatment using YFP as an inert filler instead of mCherry-actin. Quantitative data are calculated from eight experiments. Mean data \pm SEM are shown. Adjusted $p$ values comparing full timelines are from repeated measures one-way ANOVA with Bonferroni correction. 


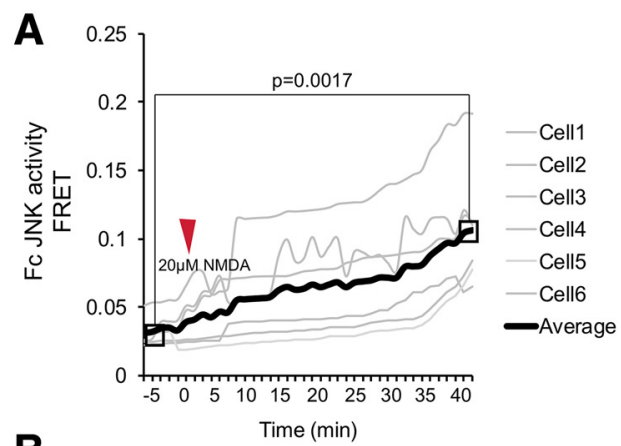

D

B
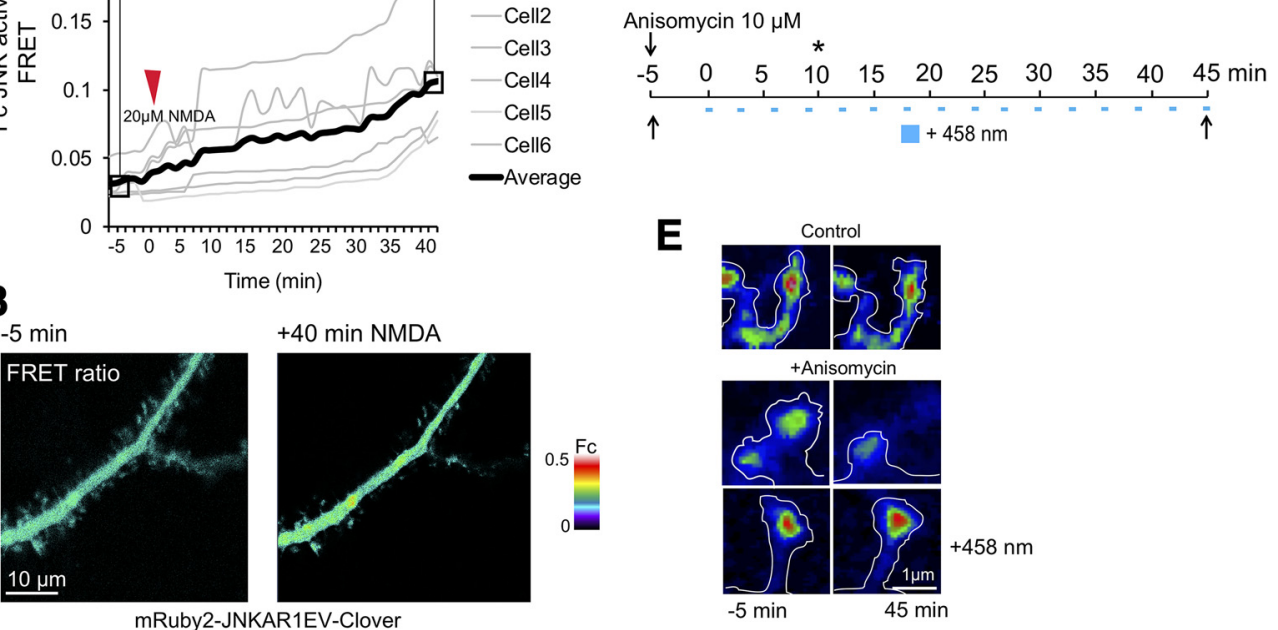

E
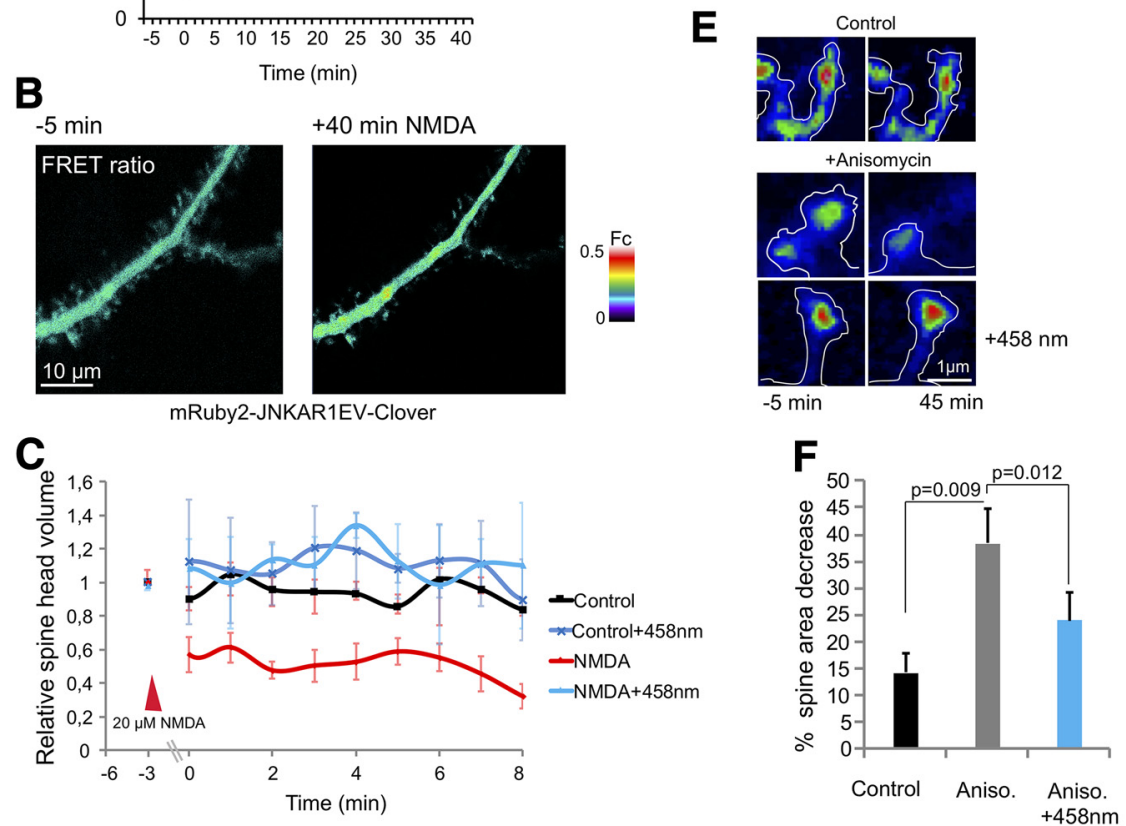

Figure 5. NMDA activates spine-head JNK and induces retraction. $\boldsymbol{A}$, Time lapse of JNK activity from mRuby2-JNKAR-1EV-Clover FRET reporter. ROI FRET (Fc) was measured from spines of 16-d hippocampal neurons before and after NMDA (20 $\mu$ M). $\boldsymbol{B}$, Representative FRET images before and after NMDA. $\boldsymbol{C}$, The estimated spine-head volume from neurons expressing mCherry-actin and LOV2-JBD before (-3 $\mathrm{min}$ ) or after treatment with NMDA are shown. Continuous photoactivation of LOV2-JBD was achieved using 1-s pulses of $458-\mathrm{nm}$ laser (3\% power) at 3-min intervals. LOV2-JBD photoactivation prevented NMDA-induced spine retraction. $\boldsymbol{D}$, The experimental setup for anisomycin $(10 \mu \mathrm{M})$ treatment and photoactivation timeline is shown. The "*" indicates time point at which JNK was activated. $\boldsymbol{E}$, Neurons were treated with or without anisomycin and spine volume measured at 45 min (as described in D). Anisomycin induced spine retraction which was prevented by LOV2-JBD photoactivation. $\boldsymbol{F}$, Mean data \pm SEM from 20-24 spines/treatment is shown. Adjusted $p$ values comparing full timelines are shown from repeated measures one-way ANOVA with Bonferroni correction.

described (Kessels et al., 2009) using a pH-luorin-tagged SEP-GluR2 which loses fluorescence when internalized to the low $\mathrm{pH}$ endocytic vesicles. Corticosterone rapidly (within $5 \mathrm{~min}$ ) reduced levels of SEP-GluR2 fluorescence at the plasma membrane in the spine head. Interestingly, this was completely blocked when JNK was inhibited by photoactivation (Fig. 4C,D). Moreover, photoactivation of LOV2-JBD prevented SEP-GluR2 internalization even when started $20 \mathrm{~min}$ after addition of corticosterone (Fig. $4 C, D)$.

We also measured the effect of corticosterone on spine-head volume. This decreased within $10 \mathrm{~min}$ of treatment with the glucocorticoid (Fig. 4C,E). Optogenetic inhibition of JNK rescued spine retraction even when light was applied 20 min after corticosterone (Fig. 4C,E). These data suggest that JNK controls GluR2 removal and regression of spines in response to corticosterone. To assess if effects of actin overexpression would skew the estimate of motility measurements, we also measured volumes and GluR2 endocytosis levels using soluble YFP. Corticosterone induced rapid reduction of SEP-GluR2 fluorescence and spine-head volume, both of which were rescued on optogenetic inhibition of JNK (Extended Data Fig. 4-1).

\section{NMDA activates JNK and induces rapid spine shrinkage}

The glutamatergic system is strongly implicated in depression (Sanacora et al., 2012). We therefore examined JNK regulation by NMDA using FRET as earlier (Figs. 2B, $4 A)$. NMDA activated JNK within minutes in dendritic and spine compartments (Fig. $5 A, B$ ). Three-minute bath application of NMDA followed by 10-min rest induced rapid spine shrinkage that was prevented by photostimulation of LOV2-JBD (Fig. 5C). We next tested anisomycin, a ribotoxin that strongly activates JNK (Fig. 2B). Anisomycin 
treatment induced $>40 \%$ reduction of spine area (Fig. $5 D-F)$.

\section{Ketamine inhibits JNK and prevents spine retraction and SEP-GluR2 receptor removal}

As NMDA is strongly activated by JNK (Fig. 5), we tested whether the NMDA receptor antagonist, fast acting anti-depressant ketamine, altered JNK activity. Indeed, JNK activity was significantly reduced after 2 h of ketamine treatment (Fig. $6 A, B$ ). However, ketamine did not prevent SEP-GluR2 removal from spines, nor did it prevent spine retraction in response to corticosterone at this time point (Fig. 6C-E). Because the timeline of these ketamine treatments was only 40 min, less than the $2 \mathrm{~h}$ required to inhibit JNK (Fig. $6 A, B$ ), we tested whether a 2-h pre-treatment with ketamine would prevent corticosterone-induced spine retraction. This prevented corticosterone-induced spine shrinkage and inhibited GluR2 removal $(F i g .6 F, G)$. Finally, we examined whether treatment with ketamine or DJNKI-1 $2 \mathrm{~h}$ following corticosterone could rescue GluR2 internalization and spine retraction. Interestingly, inhibition of JNK $2 \mathrm{~h}$ after corticosterone recovered spine volume and GluR2 homeostasis (Fig. $6 H, I)$. Ketamine treatment did not rescue at this timepoint, likely because there was insufficient time to achieve robust JNK inhibition. These data show that prophylactic treatment with ketamine or JNK inhibitor prevents spine retraction and GluR2 removal in response to corticosterone. Inhibition of JNK supports spine regrowth and rescues corticosterone effects on molecular events in spines even in the continued presence of corticosterone.

\section{Discussion}

Structural plasticity of dendritic spines facilitates elimination and regrowth of synapses and provides a fundamental process for adaptive neurotransmission. Understanding the underlying mechanism is relevant for memory and learning but also for pathologies such as depression, where significant spine loss is a hallmark (Duman and Duman, 2015; Musazzi et al., 2015; Varidaki et al., 2016). Here, we identify using an optogenetic approach, that catalytically active JNK controls spine stability from within the spine-head. Using arithmetic difference projections to quantify mCherryactin displacements over time, we observe a clear reduction of movement in spines commencing within seconds of LOV2-JBD photostimulation to inhibit JNK solely in the spine-head. This rapid response indicates a proximal mechanism whereby JNK acts directly in the spine to suppress motility. Full recovery of spine movement after photostimulation is ended takes $\sim 2 \mathrm{~min}$, consistent with the photo-cycle of LOV2-JBD which lasts $\sim 80 \mathrm{~s}$, after which a constrained state for LOV2-JBD is expected to reestablish (Zayner and Sosnick, 2014).

We show that JNK predominantly regulates spines with smaller head to neck length ratios, suggesting a more pronounced control of thin spines. This spine class emerge as motile protrusions during new synapse formation, enriched with dynamic actin (Engert and Bonhoeffer, 1999; Lendvai et al., 2000; Matsuzaki et al., 2004; Cingolani and Goda, 2008), and is prominent throughout life during synapse formation (Fischer et al., 2000; Holtmaat et al., 2008). Our data establish that physiologically active JNK controls actin dynamics locally in thin spines.

We show using temporal color coding that optogenetic inhibition of JNK alters the actin pool at the periphery of the spine rather than in the central region closer to the base of the spine and neck. The peripheral pool of F-actin in this region has been shown to turnover rapidly with a half-life of around $10 \mathrm{~s}$ compared to the stable pool of cross linked F-actin at the spine center which has a half-life of $17 \mathrm{~min}$ (Honkura et al., 2008; Kasai et al., 2010; Bertling et al., 2016). Interestingly, the dynamic F-actin pool in the peripheral domain that JNK controls is the same pool that regulates AMPA receptor membrane trafficking (Cingolani et al., 2008; Honkura et al., 2008), a central event during synaptic plasticity changes (Huganir and Nicoll, 2013). Consistent with this, we find that corticosterone-activated JNK facilitates rapid (within 5 $\mathrm{min}$ ) removal of SEP-GluR2 from the spine-head membrane before spine retraction. This is blocked on optogenetic inhibition of JNK in spines. As the GluR2 subunit is associated predominantly with functional synapses (Passafaro et al., 2001), these thin spines that are controlled by JNK most likely represent immature synapses. Thus, our data uncovers that JNK activity reduces spine-head actin dynamics in the peripheral domain which is permissive for receptor removal. This mechanism may be relevant for LTD and impaired short-term memory regulation by JNK where AMPA receptor removal plays a central role in downregulation of synaptic function (Bevilaqua et al., 2003; Li et al., 2007; Myers et al., 2012).

Prolonged hyperactivity of the Hypothalamic-PituitaryAdrenal (HPA) axis leading to elevated glucocorticoids is associated with psychiatric disorders, in particular depression and anxiety (Malhi and Mann, 2018). Both endocrine and glutamate stress have been shown to induce synapse regression and dendritic atrophy that can lead to maladaptive circuit changes and depressive behaviors (Musazzi et al., 2011; Bennett and Thomas, 2014; Duman and Duman, 2015). In mice, chronic corticosterone is used to model depression, although even acute stress can induce long-term pathologic changes at synapses (Musazzi et al., 2018). Corticosterone treatment of mice was previously shown to activate JNK in the hippocampus (Solas et al., 2013). Here, using real-time FRET to measure spatiotemporal JNK activation by corticosterone, we find that spine-head JNK is activated within $10 \mathrm{~min}$ of treatment, followed by a second phase of activation after 20 $\mathrm{min}$. This could be a consequence of increased glutamate efflux which occurs following corticosterone (Musazzi et al., 2010, 2017; Sanacora et al., 2012; Treccani et al., 2014), as we show that the NMDA receptor activates spine-head JNK within this timeframe. The downstream effect of corticosterone-activated JNK is the rapid removal of SEP-GluR2 from synapses which occurs by $5 \mathrm{~min}$, followed by spine retraction commencing 10 min after corticosterone. Moreover, spine regrowth after corticosterone treatment can be recovered in spines where JNK is inhibited, up to $20 \mathrm{~min}$ after corticosterone addition. These data indicate that JNK activity regulates early events leading to spine retraction following corticosterone stress, whereas inhibition of JNK 
A

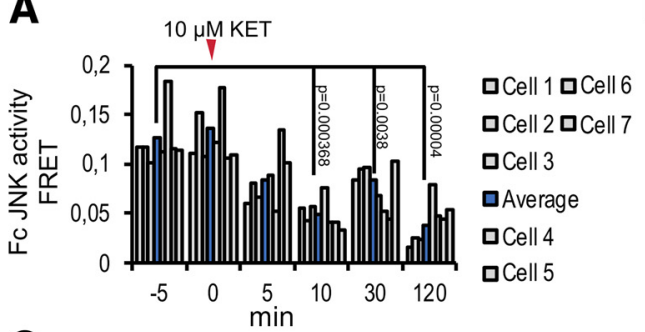

C

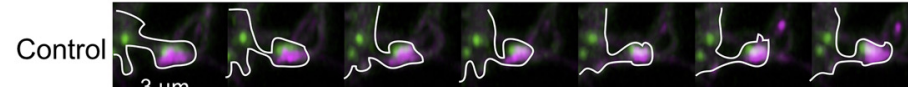
KET
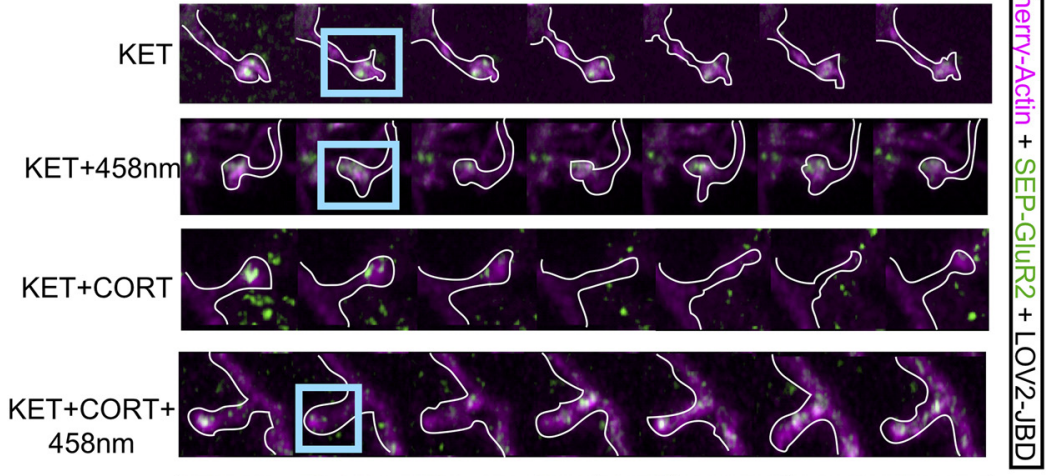

$458 \mathrm{~nm}$
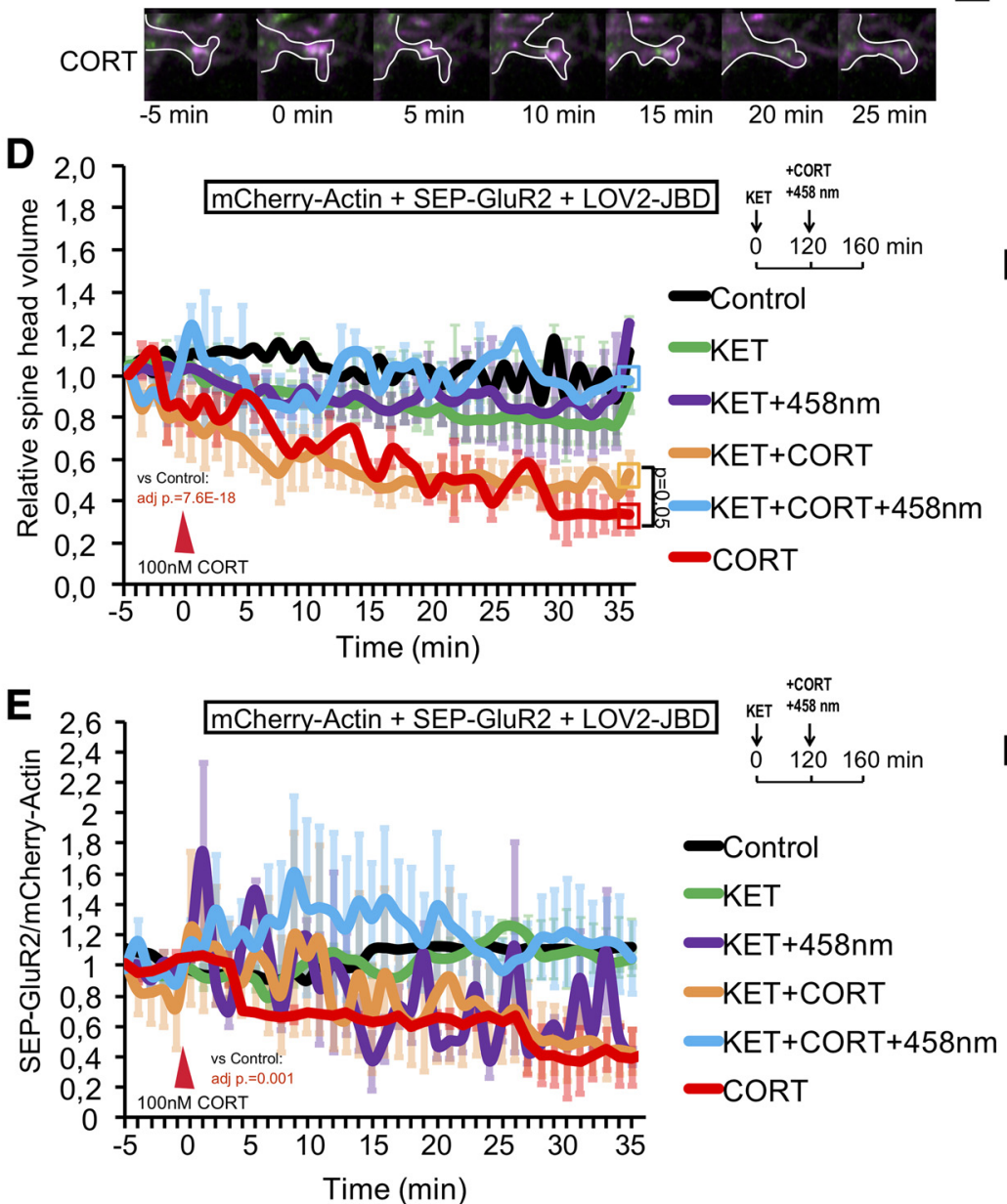

- Control

KET

$-\mathrm{KET}+458 \mathrm{~nm}$

KET+CORT

KET+CORT+458nm

-CORT
$\mathbf{F}$
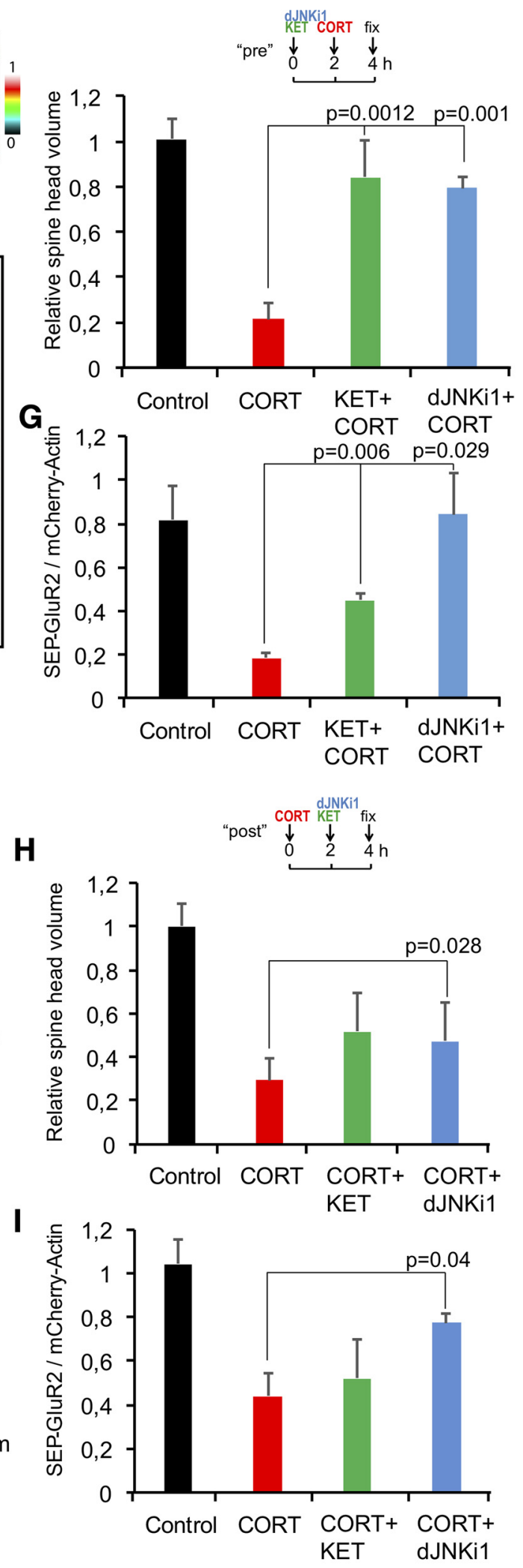

Figure 6. Ketamine inhibits JNK and prevents spine regression when given prophylactically, whereas JNK inhibition provides more robust rescue even $2 \mathrm{~h}$ after CORT. $\boldsymbol{A}$, We tested the effect of ketamine (10 $\mu \mathrm{M})$ on JNK activity in 16-d hippocampal neurons using the mRuby2-JNKAR1EV-Clover FRET reporter. FC FRET responses in spine-head ROls are from 7 separate experiments plotted 


\section{continued}

individually; $p$ values are shown from repeated measures one-way ANOVA with Bonferroni correction. Ketamine inhibited JNK activity, visible by 10 min postaddition. $\boldsymbol{B}$, The effect was long lasting. Representative FRET ratio images show mRuby2-JNKAR1EV-Clover JNK activity reporter FRET before and $2 \mathrm{~h}$ following ketamine. $\boldsymbol{C}$, Representative images of 16-d hippocampal neurons expressing mCherry-actin (magenta), SEP-GluR2 (green) \pm LOV2-JBD. Cells were stimulated with $100 \mathrm{nM}$ corticosterone (CORT) or $10 \mu \mathrm{M}$ ketamine (KET), as indicated. Blue boxes indicate ROI where 458-nm light was applied (1-s pulses at 3-min intervals) to photoactivate LOV2-JBD. $\boldsymbol{D}$, Estimated spine volume changes were calculated from multiple images as shown in $\boldsymbol{C}$, normalized to baseline. Eight cells, four spines per cell were used. E, Quantitative data of cell surface SEP-GluR2 (SEP-Glur2 fluorescence/mCherry-actin fluorescence) are shown from the same cells as in $\boldsymbol{D}$. Measurements are from eight experiments. $\boldsymbol{F}$, Dendritic spine volume changes were calculated from cells pretreated with $10 \mu \mathrm{M}$ ketamine or $10 \mu \mathrm{M}$ DJNKI-1 (to inhibit JNK) 2 h before addition of CORT (100 nM) for 2 h. G, Cell surface SEP-GluR2 levels (SEP-GluR2 fluorescence/mCherry-actin fluorescence) was measured from the same cells. $\boldsymbol{H}$, Estimated spine volume changes were from more than or equal to eight experiments; $16-\mathrm{d}$ neurons were treated with CORT (100 $\mathrm{nM})$ for $2 \mathrm{~h}$ followed by KET $(10 \mu \mathrm{M})$ or DJNKI-1 $(10 \mu \mathrm{M})$. Estimated spine volume was measured and volume at $4 \mathrm{~h}$ was expressed relative to control. I, Cell surface GluR2 levels (SEP-GluR2/mCherry-actin) were calculated from the same cells. Mean data \pm SEM are shown. Adjusted $p$ values are shown from repeated measures one-way ANOVA with Bonferroni correction.

promotes spine regrowth, even under conditions of maintained endocrine stress.

Strengthening and weakening of synaptic transmission is controlled by NMDA. High-frequency stimulation of the NMDAR coincident with pre-synaptic activity induces spine growth and synapse strengthening, whereas NMDA in the context of chemical-LTD induces spine shrinkage (Zhou et al., 2004). Here, we use the chemical LTD protocol (Lee et al., 1998), which is believed to mimic low level long lasting NMDA receptor stimulation leading to down regulation of postsynaptic AMPARs and synapse regression (Lee et al., 1998; Lüscher and Malenka, 2012). This LTD protocol induces a reduction in relative spinehead volume within $3 \mathrm{~min}$, which is completely rescued on LOV2-JBD photoactivation. These results suggest that JNK activation locally within the spine may facilitate LTD. Consistent with this possibility, JNK1 has been previously implicated in LTD both in inhibitor DJNKI1 and Jnk1-/knockout studies (Ge et al., 2007; Li et al., 2007), although the nuclear substrate c-Jun is not involved as Jun-AA mice undergo normal LTD (Seo et al., 2012).

We find that either ketamine or JNK inhibition promote hippocampal neuron spine recovery and SEP-GluR2 receptor trafficking in response to corticosterone. Moreover, we identify that ketamine treatment leads to rundown of JNK activity in a relatively slow and phasic manner. Nonetheless, JNK inhibition may be a critical downstream mediator of ketamine action. The kinetics of ketamine action on spines lags behind that of JNK inhibition, consistent with JNK inhibition being a necessary downstream event. Clearly more work will be needed to establish whether JNK inhibition contributes to ketamine action on spines in hippocampus and to determine whether this action serves any consequence in circuit remodeling. Although ketamine regulation of spines in prefrontal cortex has been dissociated from its behavioral effect in mice (Moda-Sava et al., 2019), the relevance of ketamine or JNK inhibition on spine dynamics in hippocampus has not been studied in the context of depression. It is worth noting however, that like ketamine, Jnk1 deletion or JNK inhibition using the same peptide inhibitor that is encoded in our optogenetic tool, lowers anxietyand depressive-like behaviors in mice (Hollos et al., 2018; Mohammad et al., 2018).
Optogenetic inhibition of JNK has allowed us to identify that JNK controls the dynamics of spine-head actin from within the spine where it controls corticosterone-induced and chemical-LTD-induced spine plasticity. These findings describe a previously unknown role for JNK in structural plasticity of synapses in the context of endocrine stress where JNK triggers rapid receptor removal and spine regression.

\section{References}

Attardo A, Fitzgerald JE, Schnitzer MJ (2015) Impermanence of dendritic spines in live adult CA1 hippocampus. Nature 523:592596.

Basu S, Saha PK, Roszkowska M, Magnowska M, Baczynska E, Das N, Plewczynski D, Wlodarczyk J (2018) Quantitative 3-D morphometric analysis of individual dendritic spines. Sci Rep 8:3545.

Bennett S, Thomas AJ (2014) Depression and dementia: cause, consequence or coincidence? Maturitas 79:184-190.

Berry KP, Nedivi E (2017) Spine dynamics: are they all the same? Neuron 96:43-55.

Bertling E, Englund J, Minkeviciene R, Koskinen M, Segerstråle M, Castrén E, Taira T, Hotulainen P (2016) Actin tyrosine-53phosphorylation in neuronal maturation and synaptic plasticity. $J$ Neurosci 36:5299-5313.

Bevilaqua LR, Kerr DS, Medina JH, Izquierdo I, Cammarota M (2003) Inhibition of hippocampal Jun N-terminal kinase enhances shortterm memory but blocks long-term memory formation and retrieval of an inhibitory avoidance task. Eur J Neurosci 17:897-902.

Björkblom B, Ostman N, Hongisto V, Komarovski V, Filén JJ, Nyman TA, Kallunki T, Courtney MJ, Coffey ET (2005) Constitutively active cytoplasmic c-Jun $\mathrm{N}$-terminal kinase 1 is a dominant regulator of dendritic architecture: role of microtubule-associated protein 2 as an effector. J Neurosci 25:6350-6361.

Björkblom B, Padzik A, Mohammad H, Westerlund N, Komulainen E, Hollos $\mathrm{P}$, Parviainen L, Papageorgiou AC, Iljin K, Kallioniemi O, Kallajoki M, Courtney MJ, Mågård M, James P, Coffey ET (2012) C-Jun N-terminal kinase phosphorylation of MARCKSL1 determines actin stability. Mol Cell Biol 32:3513-3526.

Bonny C, Oberson A, Negri S, Sauser C, Schorderet DF (2001) Cell-permeable peptide inhibitors of JNK: novel blockers of betacell death. Diabetes 50:77-82.

Borsello T, Clarke PG, Hirt L, Vercelli A, Repici M, Schorderet DF, Bogousslavsky J, Bonny C (2003) A peptide inhibitor of C-Jun $\mathrm{N}$-terminal kinase protects against excitotoxicity and cerebral ischemia. Nat Med 9:1180-1186.

Brecht S, Kirchhof R, Chromik A, Willesen M, Nicolaus T, Raivich G, Wessig J, Waetzig V, Goetz M, Claussen M, Pearse D, Kuan CY, Vaudano E, Behrens A, Wagner E, Flavell RA, Davis RJ, Herdegen $\mathrm{T}$ (2005) Specific pathophysiological functions of JNK isoforms in the brain. Eur J Neurosci 21:363-377. 
Cano E, Hazzalin CA, Mahadevan LC (1994) Anisomycin-activated protein kinases p45 and p55 but not mitogen-activated protein kinases ERK-1 and -2 are implicated in the induction of c-fos and c-jun. Mol Cell Biol 14:7352-7362.

Chen F, Madsen TM, Wegener G, Nyengaard JR (2010) Imipramine treatment increases the number of hippocampal synapses and neurons in a genetic animal model of depression. Hippocampus 20:1376-1384.

Cingolani LA, Goda Y (2008) Actin in action: the interplay between the actin cytoskeleton and synaptic efficacy. Nat Rev Neurosci 9:344-356.

Cingolani LA, Thalhammer A, Yu LM, Catalano M, Ramos T, Colicos MA, Goda Y (2008) Activity-dependent regulation of synaptic AMPA receptor composition and abundance by beta3 integrins. Neuron 58:749-762.

Coffey ET (2014) Nuclear and cytosolic JNK signalling in neurons. Nat Rev Neurosci 15:285-299.

Coffey ET, Hongisto V, Dickens M, Davis RJ, Courtney MJ (2000) Dual roles for C-Jun N-terminal kinase in developmental and stress responses in cerebellar granule neurons. J Neurosci 20:76027613.

Costello DA, Herron CE (2004) The role of c-Jun N-terminal kinase in the A beta-mediated impairment of LTP and regulation of synaptic transmission in the hippocampus. Neuropharmacology 46:655662.

Curran BP, Murray HJ, O'Connor JJ (2003) A role for c-Jun $\mathrm{N}$-terminal kinase in the inhibition of long-term potentiation by interleukin-1beta and long-term depression in the rat dentate gyrus in vitro. Neuroscience 118:347-357.

Duman CH, Duman RS (2015) Spine synapse remodeling in the pathophysiology and treatment of depression. Neurosci Lett 601: 20-29.

Duman RS (2009) Neuronal damage and protection in the pathophysiology and treatment of psychiatric illness: stress and depression. Dialogues Clin Neurosci 11:239-255.

Duman RS, Aghajanian GK (2012) Synaptic dysfunction in depression: potential therapeutic targets. Science 338:68-72.

Duman RS, Li N, Liu RJ, Duric V, Aghajanian G (2012) Signaling pathways underlying the rapid antidepressant actions of ketamine. Neuropharmacology 62:35-41.

Engert F, Bonhoeffer T (1999) Dendritic spine changes associated with hippocampal long-term synaptic plasticity. Nature 399:6670.

Fischer M, Kaech S, Knutti D, Matus A (1998) Rapid actin-based plasticity in dendritic spines. Neuron 20:847-854.

Fischer M, Kaech S, Wagner U, Brinkhaus H, Matus A (2000) Glutamate receptors regulate actin-based plasticity in dendritic spines. Nat Neurosci 3:887-894.

Ge S, Yang C, Hsu KS, Ming GL, Song H (2007) A critical period for enhanced synaptic plasticity in newly generated neurons of the adult brain. Neuron 54:559-566.

Hajszan T, Dow A, Warner-Schmidt JL, Szigeti-Buck K, Sallam NL, Parducz A, Leranth C, Duman RS (2009) Remodeling of hippocampal spine synapses in the rat learned helplessness model of depression. Biol Psychiatry 65:392-400.

Halavaty AS, Moffat K (2007) N- and C-terminal flanking regions modulate light-induced signal transduction in the LOV2 domain of the blue light sensor phototropin 1 from Avena sativa. Biochemistry 46:14001-14009.

Hanley JG (2014) Actin-dependent mechanisms in AMPA receptor trafficking. Front Cell Neurosci 8:381.

Harper SM, Christie JM, Gardner KH (2004) Disruption of the LOVJalpha helix interaction activates phototropin kinase activity. Biochemistry 43:16184-16192.

Heo YS, Kim SK, Seo CI, Kim YK, Sung BJ, Lee HS, Lee JI, Park SY, Kim JH, Hwang KY, Hyun YL, Jeon YH, Ro S, Cho JM, Lee TG, Yang CH (2004) Structural basis for the selective inhibition of JNK1 by the scaffolding protein JIP1 and SP600125. EMBO J 23:21852195.
Hollos P, Marchisella F, Coffey ET (2018) JNK regulation of depression and anxiety. Brain Plast 3:145-155.

Holtmaat A, Caroni P (2016) Functional and structural underpinnings of neuronal assembly formation in learning. Nat Neurosci 19:15531562.

Holtmaat A, De Paola V, Wilbrecht L, Knott GW (2008) Imaging of experience-dependent structural plasticity in the mouse neocortex in vivo. Behav Brain Res 192:20-25.

Honkura N, Matsuzaki M, Noguchi J, Ellis-Davies GC, Kasai H (2008) The subspine organization of actin fibers regulates the structure and plasticity of dendritic spines. Neuron 57:719-729.

Hruska M, Henderson N, Le Marchand SJ, Jafri H, Dalva MB (2018) Synaptic nanomodules underlie the organization and plasticity of spine synapses. Nat Neurosci 21:671-682.

Huganir RL, Nicoll RA (2013) AMPARs and synaptic plasticity: the last 25 years. Neuron 80:704-717.

Kasai H, Fukuda M, Watanabe S, Hayashi-Takagi A, Noguchi J (2010) Structural dynamics of dendritic spines in memory and cognition. Trends Neurosci 33:121-129.

Kessels HW, Kopec CD, Klein ME, Malinow R (2009) Roles of stargazin and phosphorylation in the control of AMPA receptor subcellular distribution. Nat Neurosci 12:888-896.

Komatsu N, Aoki K, Yamada M, Yukinaga H, Fujita Y, Kamioka Y, Matsuda M (2011) Development of an optimized backbone of FRET biosensors for kinases and GTPases. Mol Biol Cell 22:46474656.

Komulainen E, Zdrojewska J, Freemantle E, Mohammad H, Kulesskaya N, Deshpande P, Marchisella F, Mysore R, Hollos P, Michelsen KA, Mågard M, Rauvala $\mathrm{H}$, James $\mathrm{P}$, Coffey ET (2014) JNK1 controls dendritic field size in L2/3 and L5 of the motor cortex, constrains soma size, and influences fine motor coordination. Front Cell Neurosci 8:272.

Kowalchuk C, Kanagasundaram P, Belsham DD, Hahn MK (2019) Antipsychotics differentially regulate insulin, energy sensing, and inflammation pathways in hypothalamic rat neurons. Psychoneuroendocrinology 104:42-48.

Krieger E, Joo K, Lee J, Raman S, Thompson J, Tyka M, Baker D, Karplus K (2009) Improving physical realism, stereochemistry, and side-chain accuracy in homology modeling: four approaches that performed well in CASP8. Proteins 77 [Suppl 9]:114-122.

Kunde SA, Rademacher N, Tzschach A, Wiedersberg E, Ullmann R, Kalscheuer VM, Shoichet SA (2013) Characterisation of de novo MAPK10/JNK3 truncation mutations associated with cognitive disorders in two unrelated patients. Hum Genet 132:461-471.

Kyriakis JM, Avruch J (2012) Mammalian MAPK signal transduction pathways activated by stress and inflammation: a 10-year update. Physiol Rev 92:689-737.

Lee HK, Kameyama K, Huganir RL, Bear MF (1998) NMDA induces long-term synaptic depression and dephosphorylation of the GluR1 subunit of AMPA receptors in hippocampus. Neuron 21: 1151-1162.

Lendvai B, Stern EA, Chen B, Svoboda K (2000) Experiencedependent plasticity of dendritic spines in the developing rat barrel cortex in vivo. Nature 404:876-881.

Li XM, Li CC, Yu SS, Chen JT, Sabapathy K, Ruan DY (2007) JNK1 contributes to metabotropic glutamate receptor-dependent longterm depression and short-term synaptic plasticity in the mice area hippocampal CA1. Eur J Neurosci 25:391-396.

Liston C, Gan WB (2011) Glucocorticoids are critical regulators of dendritic spine development and plasticity in vivo. Proc Natl Acad Sci USA 108:16074-16079.

Lüscher C, Malenka RC (2012) NMDA receptor-dependent long-term potentiation and long-term depression (LTP/LTD). Cold Spring Harb Perspect Biol 4.

Malhi GS, Mann JJ (2018) Depression. Lancet 392:2299-2312.

Matsuzaki M, Ellis-Davies GC, Nemoto T, Miyashita Y, lino M, Kasai H (2001) Dendritic spine geometry is critical for AMPA receptor expression in hippocampal CA1 pyramidal neurons. Nat Neurosci 4:1086-1092. 
Matsuzaki M, Honkura N, Ellis-Davies GC, Kasai H (2004) Structural basis of long-term potentiation in single dendritic spines. Nature 429:761-766.

McAvoy K, Russo C, Kim S, Rankin G, Sahay A (2015) Fluoxetine induces input-specific hippocampal dendritic spine remodeling along the septotemporal axis in adulthood and middle age. Hippocampus 25:1429-1446.

McGuire JL, Depasquale EA, Funk AJ, O’Donnovan SM, Hasselfeld $\mathrm{K}$, Marwaha S, Hammond JH, Hartounian V, Meador-Woodruff JH, Meller J, McCullumsmith RE (2017) Abnormalities of signal transduction networks in chronic schizophrenia. NPJ Schizophr 3:30.

Melero-Fernandez de Mera RM, Li LL, Popinigis A, Cisek K, Tuittila M, Yadav L, Serva A, Courtney MJ (2017) A simple optogenetic MAPK inhibitor design reveals resonance between transcriptionregulating circuitry and temporally-encoded inputs. Nat Commun 8:15017.

Michelsen KA, van den Hove DL, Schmitz C, Segers O, Prickaerts J, Steinbusch HW (2007) Prenatal stress and subsequent exposure to chronic mild stress influence dendritic spine density and morphology in the rat medial prefrontal cortex. BMC Neurosci 8:107.

Moda-Sava RN, Murdock MH, Parekh PK, Fetcho RN, Huang BS, Huynh TN, Witztum J, Shaver DC, Rosenthal DL, Alway EJ, Lopez K, Meng Y, Nellissen L, Grosenick L, Milner TA, Deisseroth K, Bito $\mathrm{H}$, Kasai H, Liston C (2019) Sustained rescue of prefrontal circuit dysfunction by antidepressant-induced spine formation. Science 364.

Mohammad H, Marchisella F, Ortega-Martinez S, Hollos P, Eerola K, Komulainen E, Kulesskaya N, Freemantle E, Fagerholm V, Savontous E, Rauvala H, Peterson BD, van Praag H, Coffey ET (2018) JNK1 controls adult hippocampal neurogenesis and imposes cellautonomous control of anxiety behaviour from the neurogenic niche. Mol Psychiatry 23:362-374.

Murase S, Lantz CL, Kim E, Gupta N, Higgins R, Stopfer M, Hoffman DA, Quinlan EM (2016) Matrix Metalloproteinase-9 regulates neuronal circuit development and excitability. Mol Neurobiol 53:34773493.

Musazzi L, Milanese M, Farisello P, Zappettini S, Tardito D, Barbiero VS, Bonifacino T, Mallei A, Baldelli P, Racagni G, Raiteri M, Benfenati F, Bonanno G, Popoli M (2010) Acute stress increases depolarization-evoked glutamate release in the rat prefrontal/frontal cortex: the dampening action of antidepressants. PLoS One 5:e8566.

Musazzi L, Racagni G, Popoli M (2011) Stress, glucocorticoids and glutamate release: effects of antidepressant drugs. Neurochem Int 59:138-149.

Musazzi L, Treccani G, Popoli M (2015) Functional and structural remodeling of glutamate synapses in prefrontal and frontal cortex induced by behavioral stress. Front Psychiatry 6:60.

Musazzi L, Tornese P, Sala N, Popoli M (2017) Acute or chronic? A stressful question. Trends Neurosci 40:525-535.

Musazzi L, Tornese P, Sala N, Popoli M (2018) What acute stress protocols can tell us about PTSD and stress-related neuropsychiatric disorders. Front Pharmacol 9:758.

Myers KR, Wang G, Sheng Y, Conger KK, Casanova JE, Zhu JJ (2012) Arf6-GEF BRAG1 regulates JNK-mediated synaptic removal of GluA1-containing AMPA receptors: a new mechanism for nonsyndromic X-linked mental disorder. J Neurosci 32:1171611726.

Nimchinsky EA, Sabatini BL, Svoboda K (2002) Structure and function of dendritic spines. Annu Rev Physiol 64:313-353.

Noguchi J, Nagaoka A, Watanabe S, Ellis-Davies GC, Kitamura K, Kano M, Matsuzaki M, Kasai H (2011) In vivo two-photon uncaging of glutamate revealing the structure-function relationships of dendritic spines in the neocortex of adult mice. J Physiol 589:24472457.

Openshaw RL, Kwon J, McColl A, Penninger JM, Cavanagh J, Pratt JA, Morris BJ (2019) JNK signalling mediates aspects of maternal immune activation: importance of maternal genotype in relation to schizophrenia risk. J Neuroinflammation 16:18.
Openshaw RL, Thomson DM, Thompson R, Penninger JM, Pratt JA, Morris BJ, Dawson N (2020) Map2k7 haploinsufficiency induces brain imaging endophenotypes and behavioral phenotypes relevant to schizophrenia. Schizophr Bull 46:211-223.

Passafaro M, Piëch V, Sheng M (2001) Subunit-specific temporal and spatial patterns of AMPA receptor exocytosis in hippocampal neurons. Nat Neurosci 4:917-926.

Peter E, Dick B, Baeurle SA (2010) Mechanism of signal transduction of the LOV2-J $\alpha$ photosensor from Avena sativa. Nat Commun $1: 122$.

Qi AQ, Qiu J, Xiao L, Chen YZ (2005) Rapid activation of JNK and p38 by glucocorticoids in primary cultured hippocampal cells. J Neurosci Res 80:510-517.

Radley JJ, Anderson RM, Hamilton BA, Alcock JA, Romig-Martin SA (2013) Chronic stress-induced alterations of dendritic spine subtypes predict functional decrements in an hypothalamo-pituitaryadrenal-inhibitory prefrontal circuit. J Neurosci 33:14379-14391.

Rubio FJ, Ampuero E, Sandoval R, Toledo J, Pancetti F, Wyneken U (2013) Long-term fluoxetine treatment induces input-specific LTP and LTD impairment and structural plasticity in the CA1 hippocampal subfield. Front Cell Neurosci 7:66.

Saito SY (2009) Toxins affecting actin filaments and microtubules. Prog Mol Subcell Biol 46:187-219.

Sali A, Blundell TL (1993) Comparative protein modelling by satisfaction of spatial restraints. J Mol Biol 234:779-815.

Salomon M, Christie JM, Knieb E, Lempert U, Briggs WR (2000) Photochemical and mutational analysis of the FMN-binding domains of the plant blue light receptor, phototropin. Biochemistry 39:9401-9410.

Sanacora G, Treccani G, Popoli M (2012) Towards a glutamate hypothesis of depression: an emerging frontier of neuropsychopharmacology for mood disorders. Neuropharmacology 62:63-77.

Sclip A, Tozzi A, Abaza A, Cardinetti D, Colombo I, Calabresi P, Salmona M, Welker E, Borsello T (2014) c-Jun N-terminal kinase has a key role in Alzheimer disease synaptic dysfunction in vivo. Cell Death Dis 5:e1019.

Seo J, Hong J, Lee SJ, Choi SY (2012) c-Jun N-terminal phosphorylation is essential for hippocampal synaptic plasticity. Neurosci Lett 531:14-19.

Sherrin T, Blank T, Hippel C, Rayner M, Davis RJ, Todorovic C (2010) Hippocampal c-Jun- $\mathrm{N}$-terminal kinases serve as negative regulators of associative learning. J Neurosci 30:13348-13361.

Sherrin T, Blank T, Todorovic C (2011) c-Jun N-terminal kinases in memory and synaptic plasticity. Rev Neurosci 22:403-410.

Solas M, Gerenu G, Gil-Bea FJ, Ramírez MJ (2013) Mineralocorticoid receptor activation induces insulin resistance through $\mathrm{c}$-Jun $\mathrm{N}$-terminal kinases in response to chronic corticosterone: cognitive implications. J Neuroendocrinol 25:350-356.

Treccani G, Musazzi L, Perego C, Milanese M, Nava N, Bonifacino T, Lamanna J, Malgaroli A, Drago F, Racagni G, Nyengaard JR, Wegener G, Bonanno G, Popoli M (2014) Acute stress rapidly increases the readily releasable pool of glutamate vesicles in prefrontal and frontal cortex through non-genomic action of corticosterone. Mol Psychiatry 19:401.

Treccani G, Ardalan M, Chen F, Musazzi L, Popoli M, Wegener G, Nyengaard JR, Müller HK (2019) S-ketamine reverses hippocampal dendritic spine deficits in flinders sensitive line rats within $1 \mathrm{~h}$ of administration. Mol Neurobiol 56:7368-7379.

Varidaki A, Mohammad H, Coffey ET (2016) Molecular mechanisms of depression, Ed 1. San Diego: Elsevier.

Wallner B, Elofsson A (2005) All are not equal: a benchmark of different homology modeling programs. Protein Sci 14:13151327.

Westerlund N, Zdrojewska J, Padzik A, Komulainen E, Björkblom B, Rannikko E, Tararuk T, Garcia-Frigola C, Sandholm J, Nguyen L, Kallunki T, Courtney MJ, Coffey ET (2011) Phosphorylation of SCG10/stathmin-2 determines multipolar stage exit and neuronal migration rate. Nat Neurosci 14:305-313.

Weston CR, Davis RJ (2007) The JNK signal transduction pathway. Curr Opin Cell Biol 19:142-149. 
Winchester CL, Ohzeki H, Vouyiouklis DA, Thompson R, Penninger JM, Yamagami K, Norrie JD, Hunter R, Pratt JA, Morris BJ (2012) Converging evidence that sequence variations in the novel candidate gene MAP2K7 (MKK7) are functionally associated with schizophrenia. Hum Mol Genet 21:4910-4921.

Wohleb ES, Terwilliger R, Duman CH, Duman RS (2018) Stressinduced neuronal colony stimulating factor 1 provokes microglia- mediated neuronal remodeling and depressive-like behavior. Biol Psychiatry 83:38-49.

Zayner JP, Sosnick TR (2014) Factors that control the chemistry of the LOV domain photocycle. PLoS One 9:e87074.

Zhou Q, Homma KJ, Poo MM (2004) Shrinkage of dendritic spines associated with long-term depression of hippocampal synapses. Neuron 44:749-757. 